NATIONAL LABORATORY

\title{
Status Report on Modeling and Analysis of Small Modular Reactor Economics
}

March 31, 2013

Prepared by

T. J. Harrison

R. E. Hale

R. J. Moses

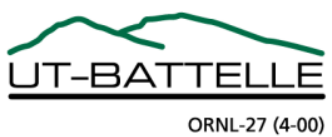




\section{DOCUMENT AVAILABILITY}

Reports produced after January 1, 1996, are generally available free via the U.S. Department of Energy (DOE) Information Bridge.

Web site http://www.osti.gov/bridge

Reports produced before January 1, 1996, may be purchased by members of the public from the following source.

National Technical Information Service

5285 Port Royal Road

Springfield, VA 22161

Telephone 703-605-6000 (1-800-553-6847)

TDD 703-487-4639

Fax 703-605-6900

E-mail info@ntis.gov

Web site http://www.ntis.gov/support/ordernowabout.htm

Reports are available to DOE employees, DOE contractors, Energy Technology Data Exchange (ETDE) representatives, and International Nuclear Information System (INIS) representatives from the following source.

Office of Scientific and Technical Information

P.O. Box 62

Oak Ridge, TN 37831

Telephone 865-576-8401

Fax 865-576-5728

E-mail reports@osti.gov

Web site http://www.osti.gov/contact.html

This report was prepared as an account of work sponsored by an agency of the United States Government. Neither the United States Government nor any agency thereof, nor any of their employees, makes any warranty, express or implied, or assumes any legal liability or responsibility for the accuracy, completeness, or usefulness of any information, apparatus, product, or process disclosed, or represents that its use would not infringe privately owned rights. Reference herein to any specific commercial product, process, or service by trade name, trademark, manufacturer, or otherwise, does not necessarily constitute or imply its endorsement, recommendation, or favoring by the United States Government or any agency thereof. The views and opinions of authors expressed herein do not necessarily state or reflect those of the United States Government or any agency thereof. 


\title{
STATUS REPORT ON MODELING AND ANALYSIS OF SMALL MODULAR REACTOR ECONOMICS
}

\author{
T. J. Harrison \\ R. E. Hale \\ R. J. Moses
}

Date Published: March 2013

Prepared by

OAK RIDGE NATIONAL LABORATORY

Oak Ridge, Tennessee 37831-6283

managed by

UT-BATTELLE, LLC

for the

U.S. DEPARTMENT OF ENERGY

under contract DE-AC05-00OR22725 



\section{CONTENTS}

\section{Page}

LIST OF FIGURES

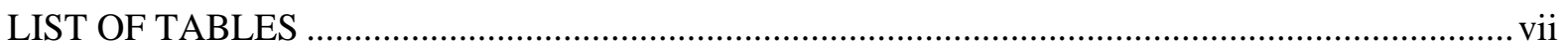

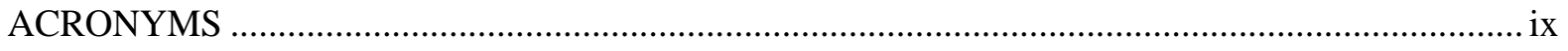

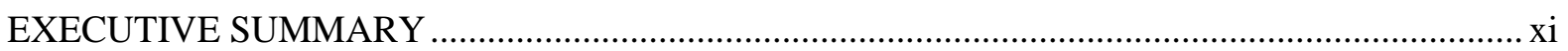

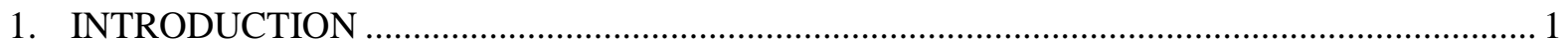

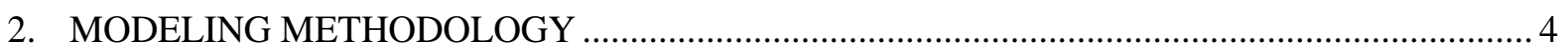

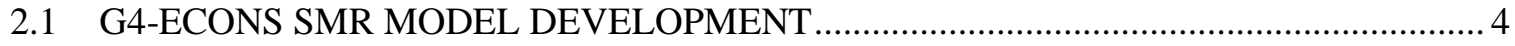

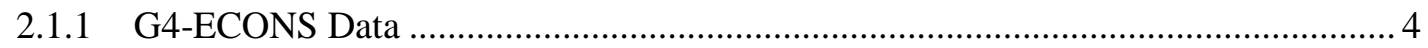

2.1.2 Modifications to G4-ECONS Model for SMR Analysis .......................................... 6

2.2 G4-ECONS SMR MODEL MIGRATION …............................................................ 9

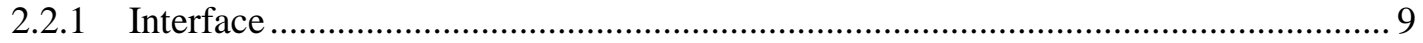

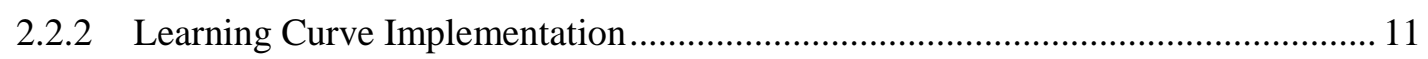

2.2.3 Migration from Excel to Mathematica................................................................... 14

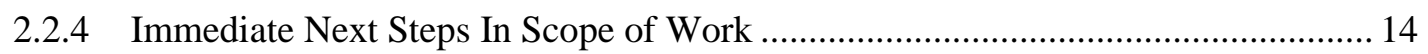

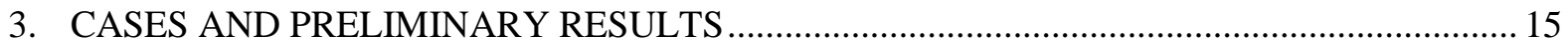

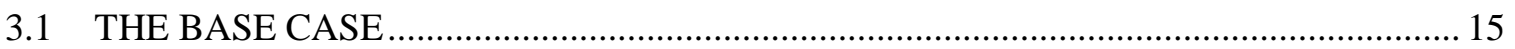

3.2 THE SMR

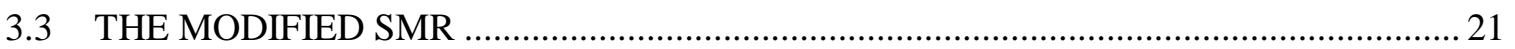

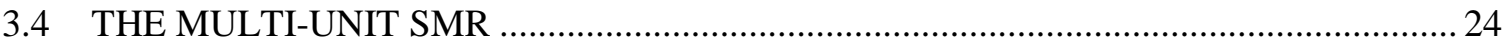

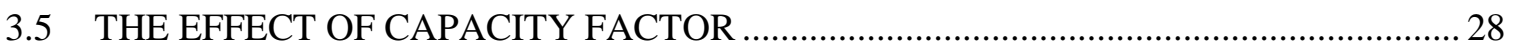

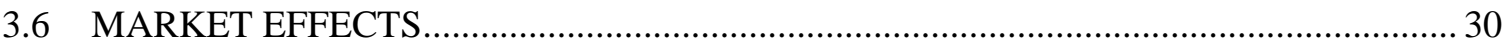

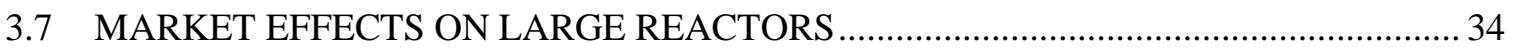

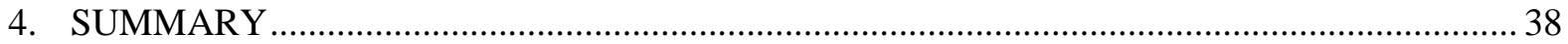

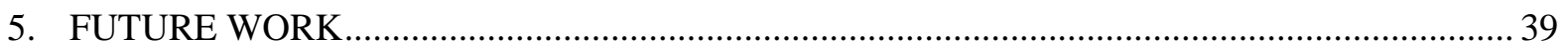

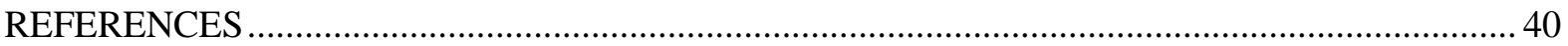





\section{LIST OF FIGURES}

Figure Page

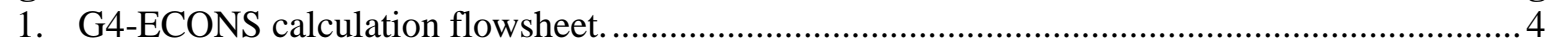

2. Capacity factor experience for recent nuclear construction............................................ 7

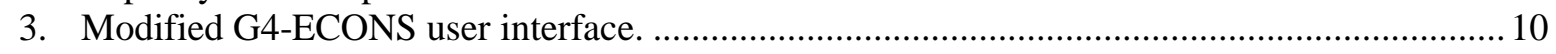

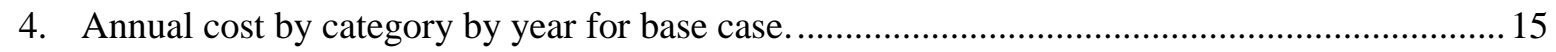

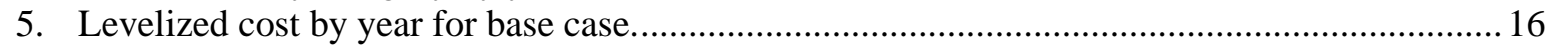

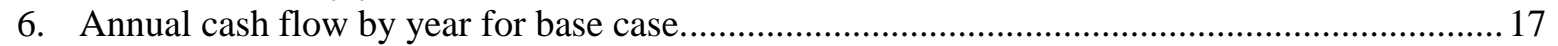

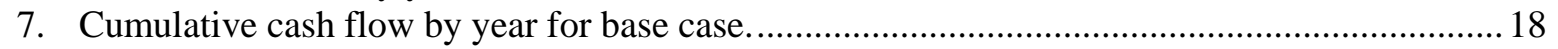

8. Discounted cumulative cash flow by year for base case. ....................................................... 19

9. Undiscounted annualized internal rate of return by year for base case. ....................................2 20

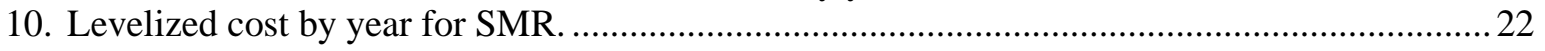

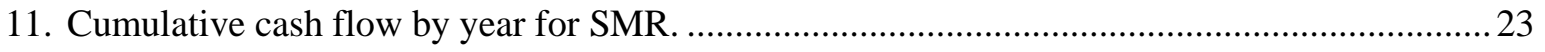

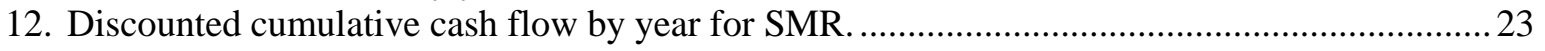

13. Undiscounted annualized internal rate of return by year for SMR.......................................... 24

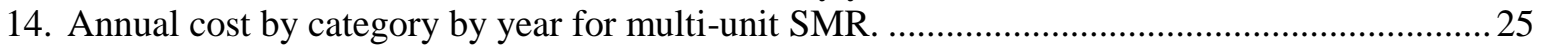

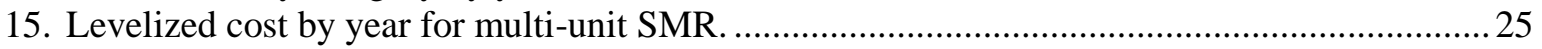

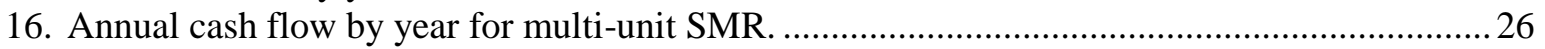

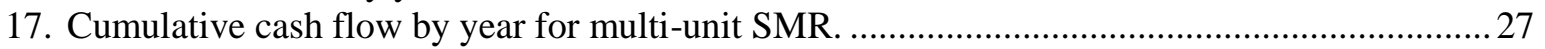

18. Discounted cumulative cash flow by year for multi-unit SMR .............................................2 27

19. Undiscounted annualized internal rate of return by year for multi-unit SMR........................... 28

20. Ramping capacity factor effect on multi-unit SMR discounted cash flow...............................29

21. Ramping capacity factor effect on multi-unit SMR internal rate of return................................29

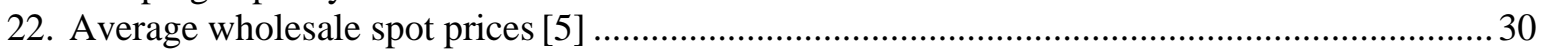

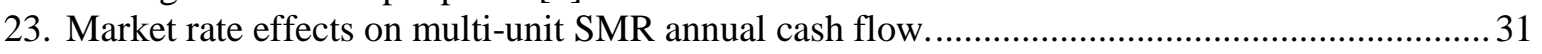

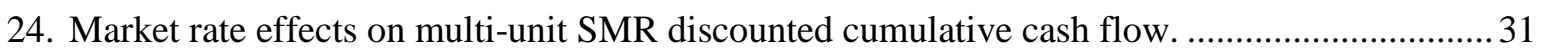

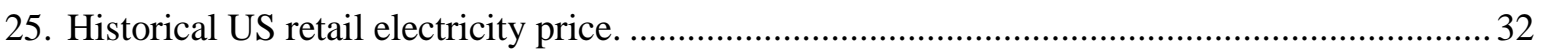

26. Future market rate effects on multi-unit SMR discounted cumulative cash flow. ....................33

27. Future market rate effects on multi-unit SMR internal rate of return....................................... 34

28. Current market rate effects on single-unit large reactor discounted cash flow........................... 35

29. Future market rate effects on single-unit large reactor discounted cash flow. .......................... 36

30. Future market rate effects on single-unit large reactor IRR. .............................................. 37 



\section{LIST OF TABLES}

Table

Page

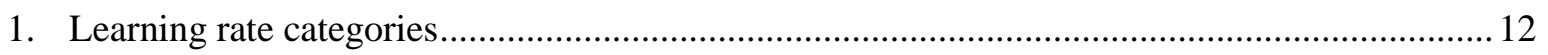

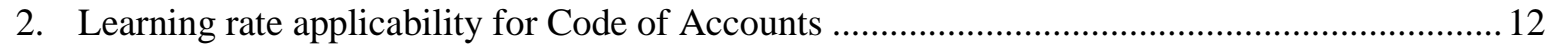





\section{ACRONYMS}

$\begin{array}{ll}\text { COTS } & \text { Commercial-off-the-shelf } \\ \text { D\&D } & \text { Decommissioning and decontamination } \\ \text { DOE } & \text { US Department of Energy } \\ \text { EMWG } & \text { Economic Modeling Working Group } \\ \text { FOAK } & \text { First of a kind } \\ \text { G4-ECONS } & \text { Generation IV Excel Calculation of Nuclear Systems } \\ \text { GIF } & \text { Generation IV International Forum } \\ \text { GWtd } & \text { Gigawatt thermal day } \\ \text { IRR } & \text { Internal rate of return } \\ \text { kgU } & \text { Kilogram uranium } \\ \text { kWe } & \text { Kilowatt electric } \\ \text { kWh } & \text { Kilowatt (electric) hour } \\ \text { kWy } & \text { Kilowatt (electric) year } \\ \text { LUEC } & \text { Levelized unit electricity cost } \\ \text { LWR } & \text { Light water reactor } \\ \text { MTHM } & \text { Metric ton of heavy metal } \\ \text { MWe } & \text { Megawatt electric } \\ \text { MWh } & \text { Megawatt (electric) hour } \\ \text { MWt } & \text { Megawatt thermal } \\ \text { NOAK } & \text { Nth of a kind } \\ \text { O\&M } & \text { Operating and maintenance } \\ \text { OECD } & \text { Organisation for Economic Co-operation and Development } \\ \text { OCOTS } & \text { One-off commercial-off-the-shelf } \\ \text { SMR } & \text { Small modular reactor } \\ \text { SWU } & \text { Separative work unit } \\ \text { UNF } & \text { Used nuclear fuel } \\ \text { UOAK } & \text { Unique one-of-a-kind } \\ & \end{array}$





\section{EXECUTIVE SUMMARY}

The recent interest in Small Modular Reactors (SMRs) from industry within the United States and around the world has spurred discussion on the benefits of the SMR versus the larger, central-station power reactor. The main thrust of this discussion on those benefits is whether a compelling economic case can be made for the deployment of SMRs when considering competition with large power reactors and other power sources.

Large reactor proponents point to the economy of scale achieved by the large nuclear stations; they generate large quantities of electricity at relatively low, stable costs. SMR proponents point to the large amount of capital required for the large nuclear station and the financial risk associated with such an endeavor versus the likely reduction in capital outlay for an SMR. If SMRs can lower the total capital barrier to deployment while maintaining a low generation cost, they can possibly usher in a new era of nuclear power expansion.

Work is ongoing at Oak Ridge National Laboratory funded by the Department of Energy's Office of Nuclear Energy under its Advanced SMR program to develop an economic model for SMR fabrication, construction, deployment, and operation, for use in determining the means and markets in which SMRs can compete successfully. This model leverages the work already performed for the Generation IV International Forum Economic Modeling Working Group and expands upon it. The resulting model performs rudimentary investment analysis from an investor perspective. Further, this model could eventually be used to develop and test policies and programs to increase the economic attractiveness of SMRs.

SMRs are expected to lower the total capital barrier by being smaller construction projects. The specific cost of SMRs in $\$ / \mathrm{kWe}$ could — and likely will — be greater than the specific cost of large reactors. However, the total capital cost for a small reactor is expected to be lower than the total capital cost of a large reactor. Given the higher $\$ / \mathrm{kWe}$, this lower total capital cost will nevertheless translate to a larger capital recovery component for generation costs. The operations and maintenance $(\mathrm{O} \& \mathrm{M})$ and fuel components of generation costs in $\$ / \mathrm{kWh}$ for a small reactor should be similar to the O\&M and fuel costs for a large reactor of a similar type (such as light water reactors). Thus, the total generation costs for SMRs should be close to, but potentially somewhat higher than, the total generation costs for new-build large reactors when accounting for the increased capital recovery component. However, if the generation cost for SMRs increases relative to the generation cost for new-build large reactors without substantially lowering the total capital barrier, then SMRs will not be economically attractive.

This report describes the status of generating an SMR-capable model and analyzing the results in the context of current market conditions and current cost estimations. As such, this is a report on the initial results using the model at this state of development. The initial results represent an opening foray into examining the potential roles and market niches of SMRs; they do not represent a final analysis on the economic viability of SMRs.

The initial results from the work described in this report reflect an analysis based on the overall model assumption of baseload generation for the wholesale electricity market. These initial results show that SMRs can potentially compete with large nuclear reactors by building multiple units at single sites. However, from an investment perspective they are not quick-turnaround investments. A single unit large reactor, or multi-unit SMR, would see discounted breakeven periods on the order of the life of the plant when collecting revenue based on current wholesale rates, and discounted breakeven 
periods on the order of decades with rates between current wholesale and retail rates.

While this assumption of wholesale electricity is generally appropriate for power generation analysis, this is not necessarily appropriate for all applications of SMRs. The power output range of the SMRs - from 10s of MWe to 100s of MWe - allows the SMR to compete in markets outside of the wholesale electricity market. For example, SMR power outputs are comparable to the requirements of industrial facilities or military installations, and these applications are more appropriately tied to the retail electricity market. Analyses of SMRs in the retail electricity market are far more favorable, with breakeven periods on the order of a single decade.

A more in-depth analysis of SMR economics will move away from this overarching assumption of wholesale markets and introduce a more flexible approach to SMR economic analysis to account for non-wholesale SMR applications. As these initial results show, a traditional approach cannot fully capture the economic benefit, and thus help make the economic case, for SMRs. Recognizing the limitations of the existing analytical toolset helps guide the further development of the SMR toolset for the duration of this project.

Besides accounting for the new market approaches that SMRs will require, future work will incorporate other energy sources into a "level playing field" economic analysis, as well as couple the economic analysis to a GIS data source to find optimal grid placement. Other future work would account for the benefit of grid stability. Additionally, future work will move from LWR-centric analyses to advanced reactor analyses, as well as the economics of multiple products, including process heat or desalination. 




\section{INTRODUCTION}

The nuclear power industries in the United States and other nations are exploring Small Modular Reactors (SMRs) for both current and future deployment. Domestically, LWR-based SMR designs have been introduced by Babcock and Wilcox, Westinghouse, NuScale, and Holtec. This interest is based on several potential benefits of SMRs relative to larger reactors; these benefits are described below. Most of these potential benefits have direct impact on the costs, and therefore economics, of SMRs. With respect to SMR economics, two overall questions must be answered. Are they economically viable? And if so, are they economically attractive?

To answer these questions, Oak Ridge National Laboratory (ORNL) is developing an SMR economic model to estimate and track construction, operation, and decommissioning and decontamination (D\&D) costs, and estimate and track revenue from selling the generated electricity on a given electricity market. When tracked as a function of time, this creates a cash flow vector that can be used to determine the breakeven period and rate of return for the investment; these values can then start to answer the question of whether SMRs are viable and attractive. Further, this model can be used to examine scenarios and policies to increase the attractiveness of SMRs.

This report describes the development and application of the tools, models, and methodologies currently under development and used to perform the SMR economic analysis and provides the initial results. It also describes the ongoing model development work and near-term and potential future expansion of the tools to provide more information for more detailed analyses.

With respect to the potential benefits mentioned above, the first potential benefit of SMRs is safety. An SMR would have a smaller core, and thus a smaller source term, to account for in an accident scenario. Further, the smaller core and lower residual heat removal requirements after shutdown may make passive safety approaches, such as natural convection cooling systems, possible. An SMR therefore could open the design space to a wider range of methods for mitigating or preventing accident scenarios. Also, this could lead to smaller emergency planning zones and exclusion zones. This could reduce operations costs from the perspective of both emergency planning and required maintenance and inspection of active safety-related systems.

However, the benefit of smaller source terms must be compared to the implications of deploying a larger number of reactors. The risk and economic effects of increasing the number of potential sources, but decreasing the potential consequences for each source, are not yet quantified, and externalities to be explored in future work.

As an added benefit, decreasing the cooling water needs may open SMR deployment to regions not amenable to water-intensive power generation. In addition, designing a reactor to operate with air cooling in normal and accident condition could completely remove geographic constraints for water supply, thereby opening nearly any inhabitable region for expansion. These regions may represent markets highly favorable for SMR deployment.

The second is the ability to more closely match existing electric grid infrastructure, increasing the number of available markets. Since the SMR rated power range is on the order of 10 s to 100 s of megawatts electric (MWe), as opposed to 1000+ MWe, this opens up more areas of the existing grid that do not require upgrades simply to bring the generated electricity to market. This increases the opportunities for SMR deployment, making them competitors in small, grid-constrained markets. 
The third potential benefit is the ability to build in stages to achieve a total power output or respond to market conditions. Again, the SMR rated power range is on the order of 10s to 100s of MWe; therefore, a potential market could be as small as 10s of MWe. As the demand in the market grows, the existing power plant site can expand to match the demand. Conversely, and perhaps more importantly, if the market does not grow, the site does not necessarily have to expand. This allows a potential operator to enter a market with the minimally required expense and expand only when favorable.

As an aside, the economics for reactors in the 10s of MWe would likely be different from reactors in the 100s of MWe. The smaller ones are more readily suited to dedicated-purpose applications, while the larger ones are more closely related to the current power plants deployed in the US. The economics of dedicated-purpose applications are coupled less to electricity markets than to the externality of the security of electric power supply; this is the subject of future work. The differentiation of these two markets, as well as the definition of the approximate breakpoint between them, is also a topic for future work.

The fourth is the lower capital cost to deploy an SMR relative to larger central-station reactors. While SMRs may have a larger specific cost (given in $\$ / \mathrm{kWe}$ ) to build, the total amount of capital required to build an SMR unit will be less simply because of the smaller size of the plant. Decreasing the total capital required increases the number of potential investors for power plant construction, and decreasing the total amount financed should decrease the cost of capital charged to those investors.

A fifth benefit is the paradigm shift from building each reactor on-site from the ground up. The general assumption for SMRs is that they will use modular construction techniques with factoryfabricated components. This is expected to result in a shorter construction period, directly leading to savings in the reduced interest accrued during construction. This would also provide overall fleet cost savings through learning curve effects by fabricating identical components in a controlled and optimized setting. However, there is a boundary condition that applies to this paradigm shift. In order to justify the capital expense of the factories to produce the components - up to and including the reactor - there must be a sufficient planned and guaranteed order book since the cost of the factory is amortized over the number of components produced. If the order book is never sufficient to justify the capital expense of a factory, the factory-based learning curve will not be realized.

At the moment, each of these benefits is still a potential or perceived benefit. For example, the safety case must be demonstrated through technological development and regulatory acceptance. There are still challenges facing designers hoping to use passive safety systems, and there are issues facing regulators who will provide oversight and guidance for licensing SMRs. Further, the cost impacts for most of these benefits are yet to be determined. For example, the financial risk premium avoided by having a smaller total capital at risk is unknown. Likewise, the actual time for construction of large reactors is uncertain, even while they are being built; the estimated time for construction of an SMR with no field experience, by necessity, must have greater uncertainty.

The analysis described in this report includes consideration of the multiple-unit build out scenario and the total capital cost comparison between large reactors and SMRs. The report also describes the general effects of learning curves on fleet deployment, but the full implementation is incomplete. The safety benefit and grid compatibility analyses represent ongoing work that will be informed by interaction with research projects examining these characteristics of SMRs.

Besides the learning curve and safety and grid effects, other near-term work will incorporate uncertainty analysis and more refined construction cost estimation. The uncertainty analysis will help 
identify the drivers of the overall system uncertainty; this will help prioritize further cost estimation efforts, such as the refined construction costs and durations.

Potential future work beyond the current scope of work might include quantifying the economic benefits derived from the other differences between SMRs and larger reactors, as well as quantifying the economic benefits and/or drawbacks of advanced, non-light-water SMRs. Also, developing modeling tools to evaluate optimized scenarios for broad-based deployment of SMRs could prove quite insightful. Examining SMRs in a dynamic market environment by modeling the incorporation of other power sources and other products, such as process heat and desalination, would provide a robust analysis capability to evaluate a wide range of SMR deployment options. 


\section{MODELING METHODOLOGY}

\subsection{G4-ECONS SMR MODEL DEVELOPMENT}

This economic model leverages the work of the Generation IV International Forum (GIF) Economic Modeling Working Group (EMWG). In 2004 the GIF EMWG commissioned the development of a Microsoft Excel-based model capable of calculating the levelized unit electricity cost (LUEC) in mills $/ \mathrm{kWh}$ (or $\$ / \mathrm{MWh}$ ) for multiple types of reactor systems being developed under the Generation IV Program; this model is now called G4-ECONS (Generation IV Excel Calculation of Nuclear Systems). The G4-ECONS tool is distributed by the Organisation for Economic Co-operation and Development (OECD), and maintained by ORNL. Figure 1 illustrates the calculation methodology.

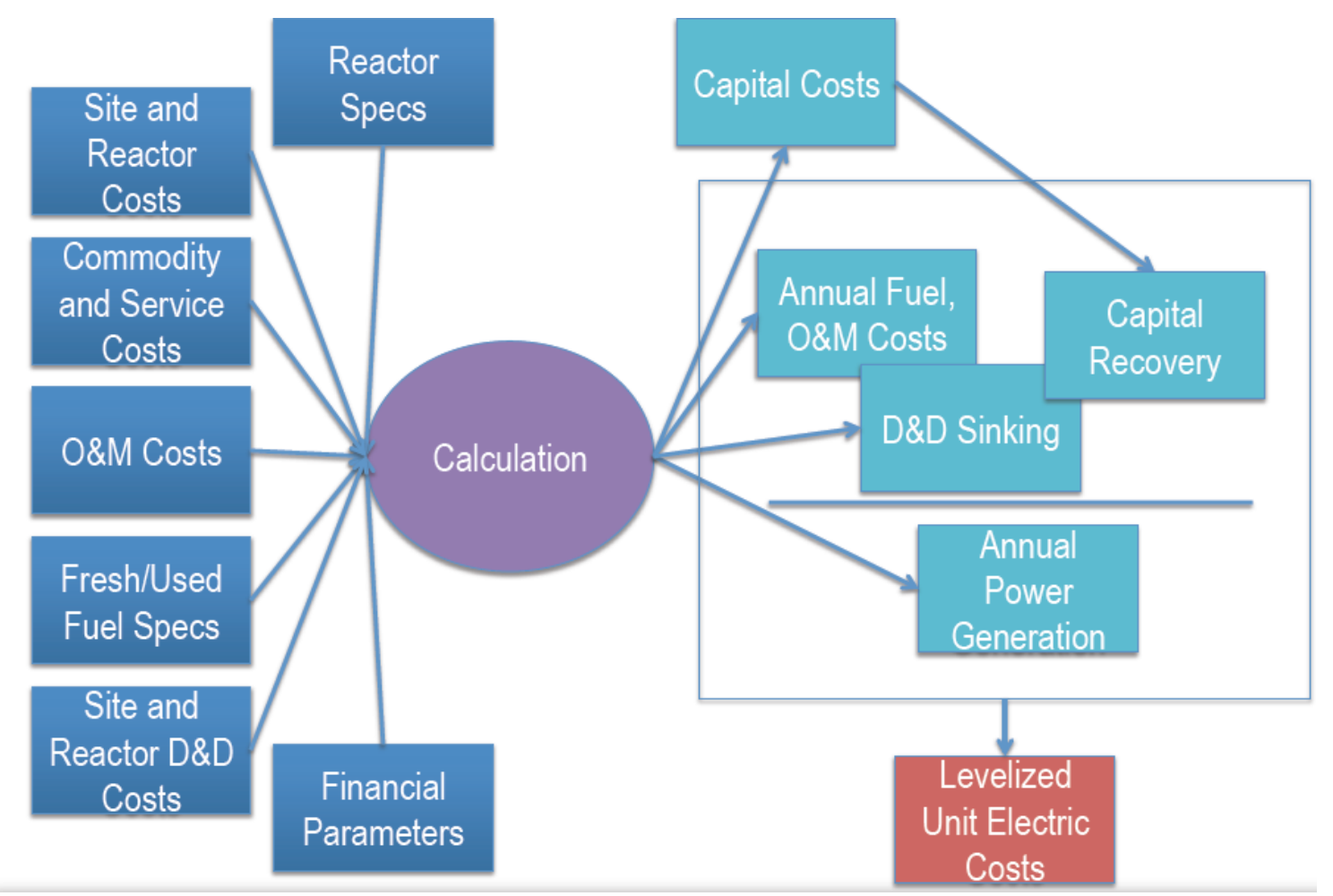

Fig. 1. G4-ECONS calculation flowsheet.

\subsubsection{G4-ECONS Data}

The current G4-ECONS inputs can be categorized as reactor information, fuel information, cost information, and financial information. G4-ECONS then calculates a total annual expense, including capital recovery, D\&D sinking fund, and annual fuel and O\&M costs, and divides the total expense by the total electricity generated, yielding a levelized unit electric cost. G4-ECONS also tracks the annual natural resources and commodity or service [such as separative work units (SWUs) of enrichment] requirements. 


\subsubsection{Reactor information}

The reactor parameters included in the current G4-ECONS model are the following:

- thermal power in megawatts thermal (MWt),

- thermal efficiency in percent,

- capacity factor in percent, and

- $\quad$ specific power in MWt/metric ton heavy metal (MTHM).

\subsubsection{Fuel information}

Fuel parameters include (but are not necessarily limited to) the following:

- fuel burnup in gigawatt thermal days (GWtd)/MTHM,

- first core enrichment in percent,

- reload core enrichment in percent, and

- used fuel composition in fraction of heavy metal elements.

\subsubsection{Cost information}

Costs associated with construction, commodities, and services include (but are not limited to) the following:

- cost of construction in $\$ / \mathrm{kWe}$,

- operating and maintenance (O\&M) costs in $\$ / \mathrm{kWy}$ and $\$ / \mathrm{MWh}$ for fixed and variable, respectively,

- $\operatorname{mining} / \mathrm{milling} /$ conversion in $\$ / \mathrm{kgU}$,

- enrichment in $\$ / S W U$,

- fuel fabrication in $\$ / \mathrm{kgU}$, and

- others (reprocessing, storage, and D\&D).

\subsubsection{Financial information}

Financial terms associated with construction, operations, and D\&D include (but are not limited to) the following:

- construction and D\&D time in years,

- operating lifetime in years,

- annually compounding interest rate during construction in percent,

- annually compounding interest rate during operation in percent,

- capital recovery period in years, and

- annually compounding interest rate for the D\&D sinking fund in percent.

\subsubsection{Outputs}

Based on these inputs, G4-ECONS calculates the following annual expenses in \$/year:

- capital recovery, 
- D\&D sinking fund,

- non-fuel O\&M, and

- fuel.

\subsubsection{Modifications to G4-ECONS Model for SMR Analysis}

Most of the inputs and outputs shown above are directly applicable to SMR analysis. However, there are some modifications necessary to make G4-ECONS more useful for more detailed economic analysis. Since ORNL is the custodian of the G4-ECONS tool for the EMWG, this modification will also be made available to the GIF for their use. Also, modifications made in the course of this work are performed on the most recent "beta" version of G4-ECONS, not the most recent publicly available version. Note that in the discussion, "current" G4-ECONS refers to the most recent beta version.

These data sets and the calculation method include inherent assumptions (discussed below) about the nuclear power plant, and these assumptions directly affect the analysis. All of these assumptions lead to a uniform annual cost. This is necessary for a levelized cost calculation - the goal of the original form of G4-ECONS - but these assumptions introduce some complications that limit the usefulness for SMR applications. Thus, SMR economic analysis requires the modification of G4-ECONS.

\subsubsection{Market rates}

The first change to G4-ECONS introduces market rates for electricity. Instead of calculating a levelized cost of electricity by dividing annual cost by annual generation, the net revenue can be calculated by multiplying the annual generation by the market rate and subtracting the annual cost. Further, this method allows annual costs to vary, which leads to the relaxation of several assumptions, as discussed below. Placing these annual net revenues into a table as a function of time can provide a more informative and useful picture of the economic parameters of interest..

\subsubsection{Steady-state operation}

The first built-in assumption to be changed is that the plant is at its steady-state operations point immediately after startup. This assumption does not account for any potential problems encountered during the first few years of operation of a new design. The operational experience of recent (last 30 years) nuclear construction shows that there is some early life variation in capacity factor [1] (Fig. 2). 


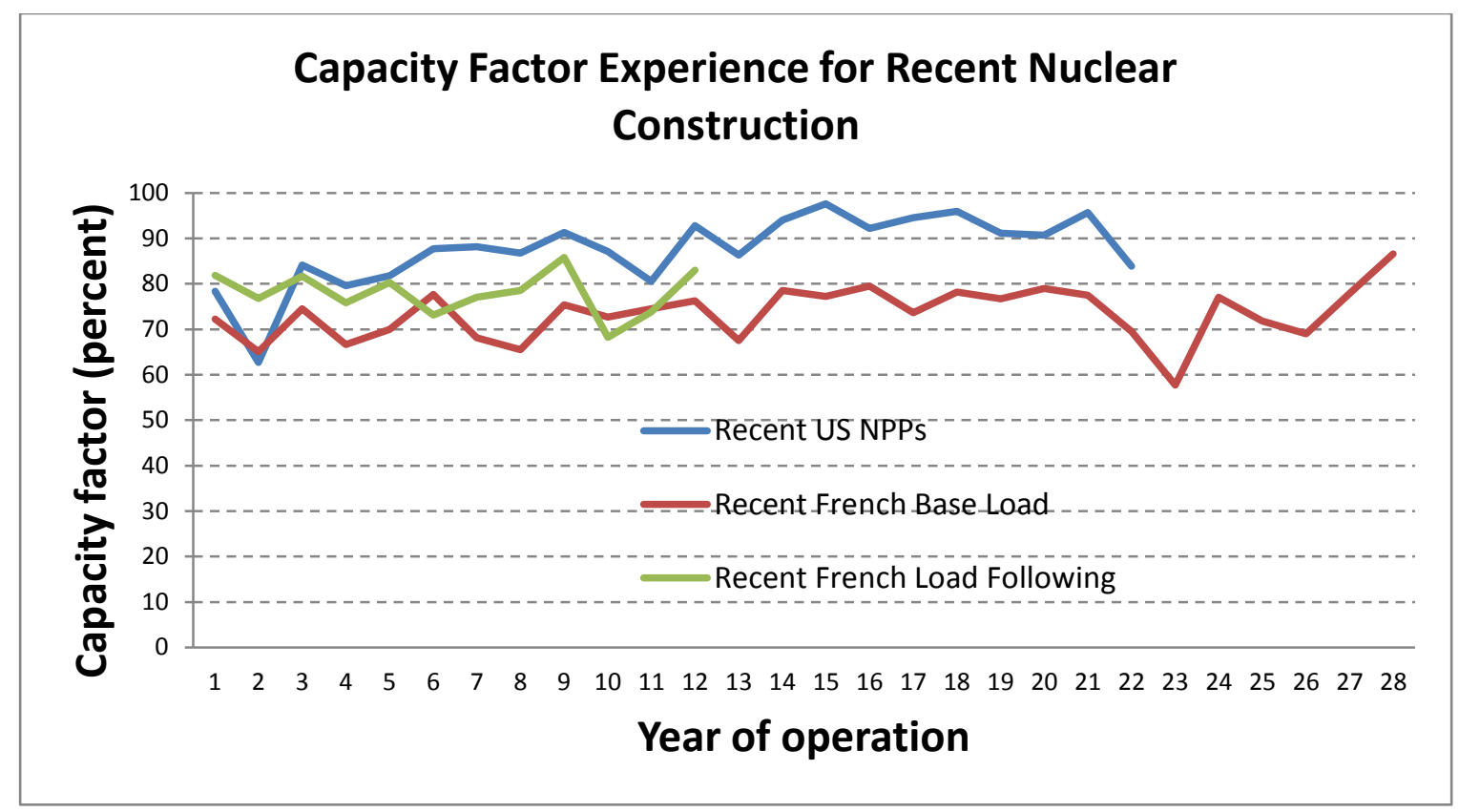

Fig. 2. Capacity factor experience for recent nuclear construction.

The NOAK perspective assumes that all new-plant problems have been accounted for; the SMR analysis necessarily does not. Historical analysis of nuclear reactor startup, as well as other power plant startup, shows that there can be several years between startup and when continuous steady-state operations are achieved. Therefore, G4-ECONS must be modified to handle time-dependent capacity factors.

This directly impacts the revenue from sales of generated electricity early in the reactor life. As the capacity factor decreases, the total amount of electricity generated and sold decreases. The only cost that decreases with decreasing capacity factor is the variable O\&M, unless the diminished capacity factor is the result of major, expensive maintenance issues. For nuclear power plants, even the fuel costs are largely independent of capacity factor; fuel is shuffled and replaced at regular intervals.

This is also important from the perspective of discounted cash flows, where income received in the present and immediate future is worth more than money received in the more distant future. Since these startup effects are in the immediate future, they have a greater effect on the cumulative discounted cash flows than capacity factor variations later in life would have. This also impacts the internal rate of return (IRR).

\subsubsection{Capital recovery}

The second assumption is that the capital recovery period is equal to the operating lifetime of the plant. This does not reflect the real-life situation of having the plant paid off well before the end of operations, nor does it reflect the potential for creative financing options. Therefore, G4-ECONS must be modified to handle arbitrary capital recovery periods.

This directly impacts the magnitude of the annual cash flows. When the capital recovery is accelerated in the first several years of operation, it negatively impacts the net revenue by increasing the already-large annual capital recovery. However, paying off the reactor early in the reactor life 
generates a long-term benefit based on the fixed market rate. This modification neither categorically diminishes nor enhances the economic performance; its effect depends on the market realities.

\subsubsection{Single-unit site}

The third, and most directly inapplicable, assumption is that there is no later expansion of generating capacity at the site. G4-ECONS calculates the cost of a single construction project, whether that is a single-unit or a double-unit construction project. One of the principal benefits of SMRs is the ability to expand generation capacity at a given site. Therefore, G4-ECONS must be modified to handle multiple-unit deployment at a single site. Notably, the initial unit can be brought online to sell power while the construction of the subsequent units is completed.

The method for handling multiple units is to assume the capital cost for the first unit includes some fraction devoted to site engineering and construction costs, and the remainder is the cost of installing the reactor and the power conversion systems. Of that site engineering and construction cost, some fraction of that is a one-time cost. When the second unit is built, the one-time costs are not incurred again.

For example, given a specific cost of $\$ 5000 / \mathrm{kWe}$, a $100 \mathrm{MWe}$ plant costs $\$ 500 \mathrm{M}$. Assuming $60 \%$ of the cost is construction $(\$ 300 \mathrm{M}), 40 \%$ of the cost is then the reactor and power conversion system $(\$ 200 \mathrm{M})$. Assuming half the initial construction cost is one-time engineering and construction, the construction cost for the second unit, and subsequent units, is $\$ 150 \mathrm{M}$. If the reactor and power conversion system still cost $\$ 200 \mathrm{M}$, the total cost for the second unit is $\$ 350 \mathrm{M}$, or $\$ 3500 / \mathrm{kWe}$. This is, obviously, the incremental cost to deploy additional units.

This averaging over the initial and subsequent incremental costs acts as a great economic benefit. In the example above, the specific cost for a single-unit site is $\$ 5000 / \mathrm{kWe}$, but the specific cost for a two-unit site is $\$ 4250 / \mathrm{kWe}$. Adding more units brings the overall specific cost closer to the incremental cost of $\$ 3500 / \mathrm{kWe}$. This modification thus introduces a different type of economy of scale - an economy of mass deployment.

Note that the SMR deployment model must account for several approaches to site construction. Placing multiple units within a single containment building has a different incremental cost structure than building an individual containment building for each unit. Further, novel containment building designs may further front-load a sequential spending profile.

For example, the NuScale design places up to 12 reactors in a single pool; the entire pool, and a minimum amount of piping and plumbing, must be completed before the first reactor can be brought online. Conversely, mPower plants can place two reactors in a single containment building before building a subsequent containment building.

\subsubsection{NOAK costs}

The fourth assumption is that all reactors of the same type have the same cost. When working in the NOAK perspective, this is a valid assumption. However, for SMR economic analysis, one assumes that the industry starts with a FOAK plant with a FOAK cost and evolves to a NOAK plant with NOAK cost by following some type of learning curve. Therefore, G4-ECONS must be modified to handle changes in reactor cost as defined by the learning curve.

For example, assume the second unit costs $90 \%$ of the first unit. Using the estimates from above for a two-unit site, the total cost for the second unit is $\$ 330 \mathrm{M}$, or $\$ 3300 / \mathrm{kWe}$. The total specific cost for 
the two-unit site is then $\$ 4150 / \mathrm{kWe}$. This modification thus introduces another different type of economy of scale-an economy of mass production.

\subsubsection{Other costs and differences}

It is anticipated that some costs will be higher for SMRs compared to large reactors. For example, O\&M costs will probably be higher on a per-kWh basis since there is some minimal staffing level regardless of the size of the reactor. The SMR "premium" for O\&M costs is unknown. Other differences, such as the cost of capital for a smaller capital at risk, are also unknown. These values are subject to further study.

\subsubsection{Progress}

To date, the first three modifications as described in Sections 2.1.2.2 through 2.1.2.4 have been fully implemented. The mathematical and operational framework for the fourth modification (learning curve) has been developed but not fully implemented.

These changes are not just applicable to SMRs. They apply to any nuclear power economics analysis that does not meet all the original assumptions of G4-ECONS. For example, no AP-1000 nuclear plants have been built and operated yet (several are under construction in China and the U.S.), therefore the AP-1000 at this time would not be considered a NOAK design. Furthermore, it would potentially have multiple units at a single site and thus does not meet all the assumptions of the current version of G4-ECONS.

\subsection{G4-ECONS SMR MODEL MIGRATION}

The current G4-ECONS model is a connected set of Microsoft Excel® worksheets. Each cell is color-coded as either an input or a calculation cell. The data entry worksheet for G4-ECONS has over 400 cells, which can be challenging for a novice user. Thus, the proficient use of this spreadsheet requires some experience. To simplify the input, another step in updating this model is to provide a more appealing interface that would allow for intuitive user interaction.

\subsubsection{Interface}

The modified user interface can be seen in Fig. 3. The interface includes links to data input cells as well as simplified categorization of the inputs and description of their purpose and applicability. The interface tool allows reactors to be summarized by type and model. It also allows for inputs, outputs, and the results of several types of analyses including uncertainty and learning curve to be summarized and displayed.

Note that the modified interface is fully compatible with the current version of G4-ECONS. Work is ongoing to make the modified interface compatible with the modified version of G4-ECONS. 


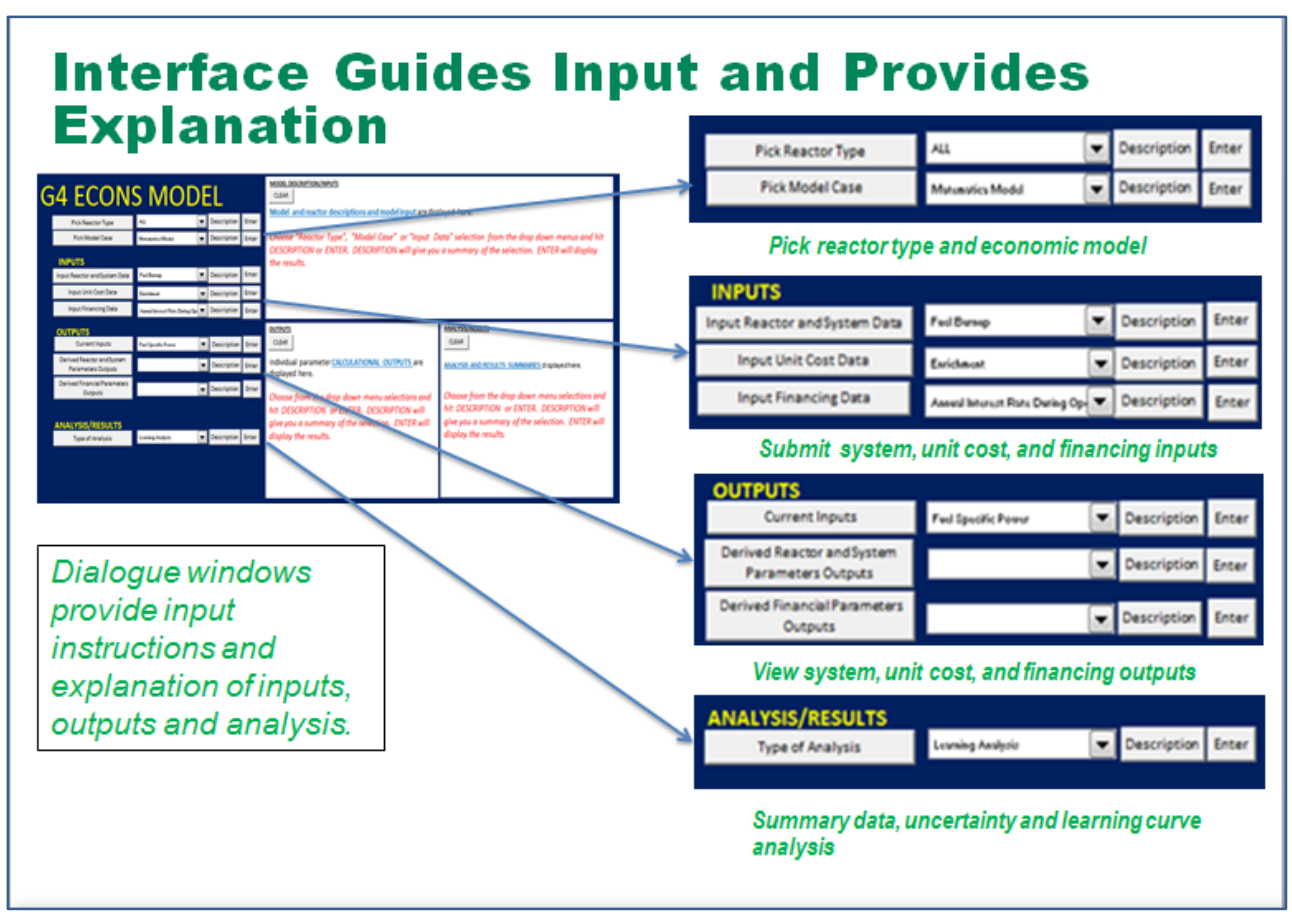

Fig. 3. Modified G4-ECONS user interface.

\subsubsection{Input}

The new interface allows users to enter individual parameters from the same types of categories as listed above. However, the user specifically chooses each parameter from a drop-down menu for entry. Upon entry, the value for that parameter populates a database specific to the case the user wishes to analyze. A description of each parameter is provided for guidance.

The database is extensible to the system or component level. For example, an LWR may have a line item of "Electrical Equipment" with a cost of \$125 M.

\subsubsection{Output}

While entering the information for the case, two types of immediate output are available. One output is a recapitulation of the input data. This is meant as a check for the user to find any input errors before proceeding.

The second output is derived data based on the input data. An example of derived data is the reactor heavy metal loading - this is a function of the power density and the total power of the reactor. This feature can also serve as a check for debugging.

\subsubsection{Results}

After ensuring all input data is correct, the user can then view any of several results. The current G4ECONS result of interest is the levelized cost. However, the modified and expanded version of G4-ECONS allows for other results, such as breakeven period and internal rate of return. 


\subsubsection{Learning Curve Implementation}

Another architectural modification to the G4-ECONS model for application to SMRs includes the application of learning curves to the fabrication of production units for SMR designs. The generic approach to learning curves is to assign a "macro" learning curve to the entire reactor. Thus, for example, a $90 \%$ learning curve means that the second reactor costs $90 \%$ of the first. Typically, the learning curve is applied to doubling. That is, the $2^{\text {nd }}$ is $90 \%$ of the $1^{\text {st }}$; the $4^{\text {th }}$ is $90 \%$ of the $2^{\text {nd }}$; the $8^{\text {th }}$ is $90 \%$ of the $4^{\text {th }}$, etc.

However, the "macro" learning curve is essentially an estimate of the aggregate learning curve. Given that a reactor is a complex machine with many individual components, each of which has its own learning curve, the aggregate learning curve can be calculated through the summation of the learning curves of the individual components. The derivation of the mathematics to handle this aggregation will be included in later reports.

There is insufficient data for precise estimation of the macro learning curve at this point. The estimation depends on at least a basic list of components and systems, their initial costs, and their respective learning curves. The list of components is highly dependent on the design, and this analysis does not have a reference design at this point. Also, the cost of the first unit is poorly defined for components that have not been designed yet. However, the characteristic learning curve can be estimated based on several factors as described in Section 2.2.2.2.

A second interpretation of the learning curve can be implemented. Assuming cost estimates are given as NOAK costs, the learning curve then can be used to estimate the FOAK cost. For example, if the $8^{\text {th }}$ unit is considered to be a NOAK unit, then a $90 \%$ learning curve implies the FOAK costs $1 / 0.9^{3}=$ $137 \%$ of the NOAK.

\subsubsection{Learning curve databases}

The databases described in Section 2.2.1.1 have fields for learning curve estimates for each component based on whether the component is commercial-off-the-shelf (COTS), one-off commercial-off-the-shelf (OCOTS), or unique one-of-a-kind (UOAK). Using the example above of "Electrical Equipment," it may be judged that for this reactor, the electrical equipment is COTS. The consequences of that choice are explained below in Table 1.

It is recognized that the full development of learning curve data for each system and component will require the application of learning curve theory as described in this report to manufacturing data as developed and supplied by vendors. Prior to the generation of this data, there are generic approaches that can capture the expected scale of savings associated with the NOAK unit based upon assumptions from design concepts for the FOAK unit.

\subsubsection{Learning curve classification}

The benefit of learning in manufacturing and construction is principally associated with the tasks using a large degree of human performance. As a machine cannot "learn," automated tasks typically have poor learning curves [2]. It is also recognized that the best estimates of learning curve improvements result from manufacturing data. In lieu of data on manufacturing of SMRs, initial estimates are necessary. The generation of best estimates will result from a combination of the learning curve theory discussed earlier in the report and actual manufacturing data. General breakdowns of expected learning curve values can be found within literature [2]. 
The proposed mapping of learning curve rate information into the COTS/OCOTS/UOAK category space is given in Table 1.

Table 1. Learning rate categories

\begin{tabular}{lc}
\hline \multicolumn{1}{c}{ Development type } & Assumed initial learning rate \\
\hline COTS (commercial off-the-shelf) & 1.0 \\
OCOTS (one-off commercial-off-the-shelf) & $0.8-0.9$ \\
UOAK (unique one of a kind) & $0.7-0.8$ \\
\hline
\end{tabular}

It is expected that a COTS component has already achieved all the learning available to it. This also assumes that no additional qualification for nuclear application is required. An OCOTS component is based on a COTS component and thus already has significant automation and optimization included - this may reflect the nuclear qualification of current COTS components. The UOAK component requires the creation of a new product, and thus has potential optimization available.

Evaluations of specific designs will be included in the model that make use of detailed estimates of work breakdown activities to determine the expected learning curve within the ranges identified for the specific design classification (i.e., COTS, OCOTS, or UOAK). The use of these initial generic estimates for learning curves will be refined with actual manufacturing data as they become available to allow for continuously improved learning curve estimates. As the SMR concepts develop, it is expected that a majority of the UOAK components will transition to the OCOTS and finally into the COTS classification with the final learning curve rates being upper bounded with a maximum potential rate of 1.0 .

To examine expanding the learning curve beyond manufacturing, an evaluation of activities associated with the G4-ECONS Code of Accounts was performed to determine applicability to potential learning activity. The results are presented in Table 2. Learning associated with other activities may also be present. In particular, site structures and improvements along with shipping and transportation costs identified in the G4-ECONS model may also be considered for potential learning.

Table 2. Learning rate applicability for Code of Accounts

\begin{tabular}{|l|l|c|}
\hline $\begin{array}{c}\text { G4-ECONS } \\
\text { code of account }\end{array}$ & Description & $\begin{array}{c}\text { Expected } \\
\text { applicability of } \\
\text { learning for } \\
\text { NOAK costs }\end{array}$ \\
\hline \multicolumn{2}{|c|}{ Capitalized Pre-construction Costs (10 series) } & Yes \\
\hline 11 & Land and land rights & No \\
\hline 12 & Site permits & No \\
\hline 13 & Plant licensing & Yes \\
\hline 14 & Plant permits & No \\
\hline 15 & Plant studies & No \\
\hline 16 & Plant reports & No \\
\hline 19 & Contingency on 11-16 above & Yes \\
\hline Capitalized Direct Cost (20 series) & Yes \\
\hline 21 & Structures and improvements (Civil) & Yes \\
\hline
\end{tabular}




\begin{tabular}{|c|c|c|}
\hline $\begin{array}{l}\text { G4-ECONS } \\
\text { code of account }\end{array}$ & Description & $\begin{array}{c}\text { Expected } \\
\text { applicability of } \\
\text { learning for } \\
\text { NOAK costs } \\
\end{array}$ \\
\hline 22 & Not applicable & N/A \\
\hline 23 & Process equipment & Yes \\
\hline 24 & Electrical equipment & Yes \\
\hline 25 & Heat rejection/cooling & Yes \\
\hline 26 & Miscellaneous plant equipment & Yes \\
\hline 27 & Special materials & Yes \\
\hline 28 & Simulator (if needed) & No \\
\hline 29 & Contingency on $21-28$ above & Yes \\
\hline \multicolumn{2}{|c|}{ Capitalized Indirect Costs (30 series) } & Yes \\
\hline 31 & Field indirect cost & Yes \\
\hline 32 & Construction supervision & Yes \\
\hline 33 & Plant commissioning services & Yes \\
\hline 34 & Plant demonstration run & Yes \\
\hline 35 & Design services offsite & Yes \\
\hline 36 & $\mathrm{PM} / \mathrm{CM}$ services offsite & Yes \\
\hline 37 & Design services onsite & Yes \\
\hline 38 & $\mathrm{PM} / \mathrm{CM}$ services onsite & Yes \\
\hline 39 & Contingency on $31-38$ above & Yes \\
\hline \multicolumn{2}{|c|}{ Capitalized Owner's Costs (40 series) } & Yes \\
\hline 41 & Staff recruitment and training & No \\
\hline 42 & Staff housing facilities & No \\
\hline 43 & Staff salary-related costs & No \\
\hline 44 & Other owners' costs & No \\
\hline 49 & Contingency on $41-46$ above & Yes \\
\hline \multicolumn{2}{|c|}{ Capitalized Supplementary Costs } & Yes \\
\hline 51 & Shipping and transportation costs & Yes \\
\hline 52 & Spare parts & Yes \\
\hline 53 & Taxes & N/A \\
\hline 54 & Insurance & N/A \\
\hline 59 & Contingency on $51-54$ above & N/A \\
\hline 63 & Interest during construction (if entered as a non-zero value) & N/A \\
\hline
\end{tabular}




\subsubsection{Migration from Excel to Mathematica}

The final upgrade of the model includes the planned migration of the model from an Excel-based tool to a web-based tool utilizing Mathematica. The goal of migration to a centralized web-based platform is twofold: (1) increase access by making G4-ECONS available without distribution limitations and (2) control input and use of model through eliminating individual distribution modifications. Currently, a customer can request G4-ECONS from OECD; placing the tool online removes that need. Once the customer has a copy of G4-ECONS, the customer can change the spreadsheet - variables, assumptions, formulas, etc. - and present the results as having come from G4-ECONS. By placing the tool online, one can also mitigate this potential problem of consistency of approach and assumptions.

The choice of modeling platform was also considered. Excel has many advantages. For example, it is used worldwide in a variety of fields, and most potential users would have some base level of familiarity. However, it has some drawbacks, specifically with the flexibility needed to handle arbitrary vectors and arrays. Relaxing some of the assumptions of the current G4-ECONS requires the ability to handle indexes and subsets of vectors. Mathematica also offers symbolic programming. Since most of the algorithms and formulas used in the analysis are formulated by hand symbolically, this is a less error-prone method for scripting. In addition, Mathematica offers more automated control over the generation of figures for visual analysis. Finally, Mathematica can handle uncertainty calculations and parametric studies more easily than Excel, making it more useful for dynamic and in-depth analyses.

Excel still has a place in handling the databases generated by the interface tool. These databases can then be fed directly to Mathematica for calculation, and the resulting outputs returned to Excel for interface reporting.

\subsubsection{Immediate Next Steps In Scope of Work}

The status of the tool is incomplete. The interface is compatible with the current G4-ECONS, not the Mathematica-based version. The learning curve is not implemented in either model, but the framework is in place. However, the work that is complete has yielded interesting results as presented in Sect. 3.0. 


\section{CASES AND PRELIMINARY RESULTS}

\subsection{THE BASE CASE}

The base case for analysis is a $1000 \mathrm{MWe}$ reactor. This is a typical $1000 \mathrm{MWe}$ LWR with a set of well-characterized costs. The costs are taken from the Advanced Fuel Cycle Cost Basis Report [3]. Note that the Cost Basis Report provides a nominal value and a bounding range for costs; this introduces uncertainty in the calculation which is not accounted for in this analysis. The assumptions for this reactor are as follows:

- $\quad 3000 \mathrm{MWt}$

- $33.3 \%$ thermal efficiency

- $90 \%$ capacity factor (constant through life)

- 5 year construction period

- 40 year lifetime

- $\$ 5000 / \mathrm{kWe}$

- D\&D costs $25 \%$ of construction

- $3 \%$ discount rate

- $\$ 100 / \mathrm{MWh}$ market rate [4]

- $5 \%$ interest rate during construction and payback

- $5 \%$ interest earned on D\&D sinking fund

- 40 year capital recovery (full lifetime)

The output of the G4-ECONS tool is presented most effectively in plots.

Annual Cost by Category

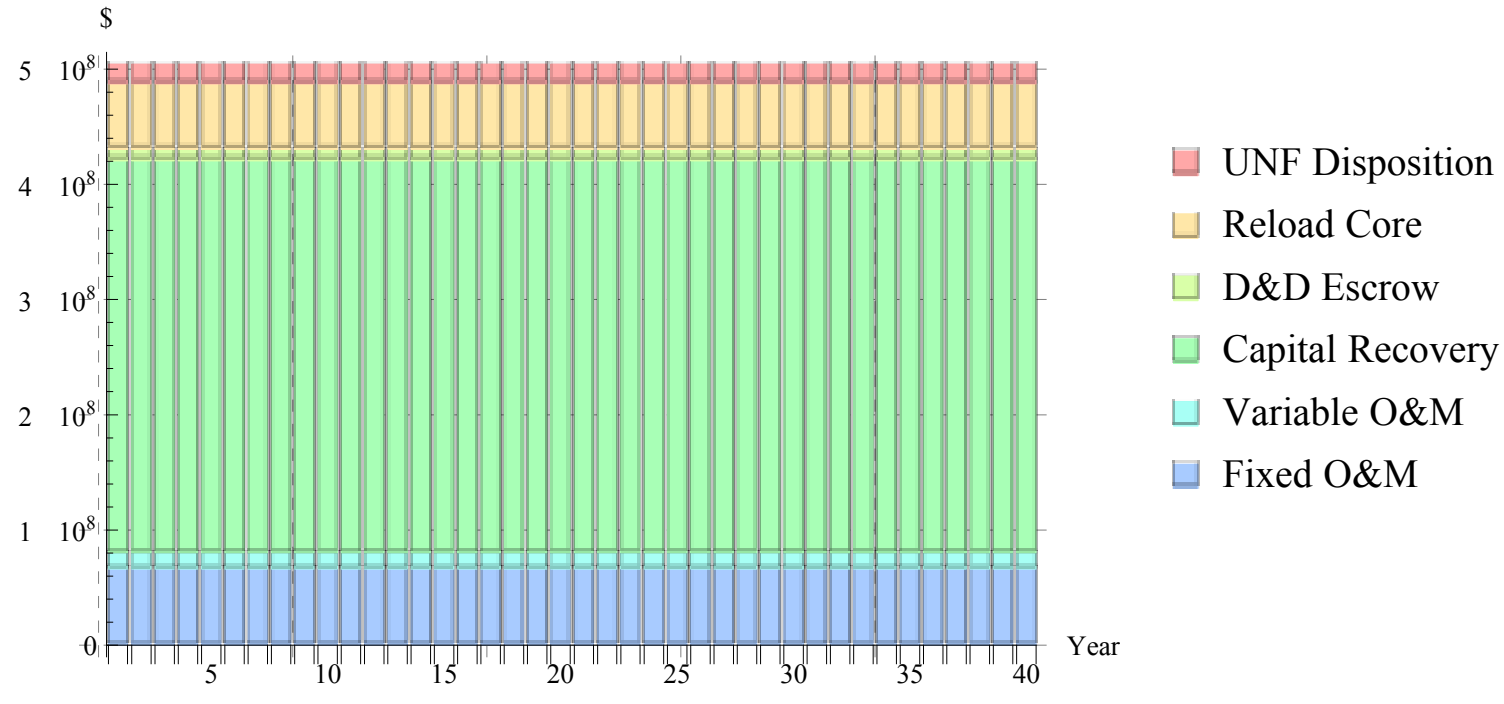

Fig. 4. Annual cost by category by year for base case.

Figure 4 shows that the total annual cost is on the order of $\$ 500 \mathrm{M}$. The majority of that is capital recovery-approximately $65 \%$. A 1000 MWe plant with a $90 \%$ capacity factor produces $7.89 \times 10^{6}$ 
MWh of electricity annually. Dividing annual cost by annual generation yields the levelized cost.

\section{Levelized Cost by Year}

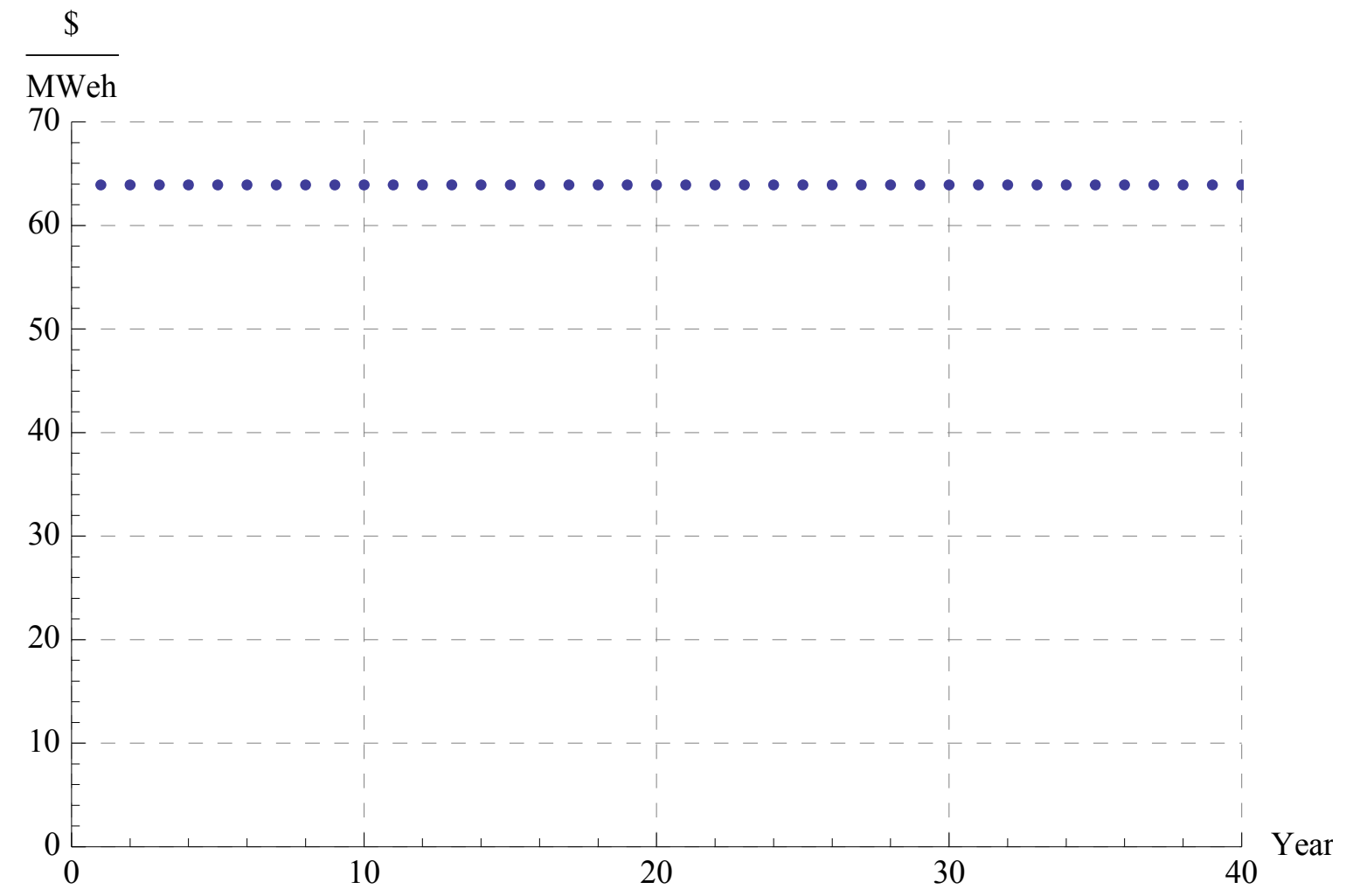

Fig. 5. Levelized cost by year for base case.

The levelized cost (Fig. 5) is also a uniform series at $\$ 64 / \mathrm{MWh}$. The breakdown for each of the categories above is:

- Used nuclear fuel (UNF) Disposition: $\$ 2.17 / \mathrm{MWh}$

- Reload Core: \$7.20/MWh

- D\&D Escrow: \$1.31/MWh

- Capital Recovery: \$43.09/MWh

- Variable O\&M: $\$ 1.80 / \mathrm{MWh}$

- Fixed O\&M: \$8.37/MWh

According to the Nuclear Energy Institute (NEI), the average cost of nuclear power is $\$ 22.90 / \mathrm{MWh}$ [5]. Excluding capital recovery and D\&D escrow, the calculated cost for this case is $\$ 19.53 / \mathrm{MWh}$, a difference of around 20\%, a fairly large difference. However, the NEI costs are 2011 costs; the Cost Basis Report costs are 2009 costs, which does account for some of the difference. An updated version of the Cost Basis Report will be issued in 2013, and the values used in the analysis will be updated to reflect this update.

The analysis is more interesting when the actual cash flow is examined. There is a large negative value at time 0 representing the construction costs, including interest, and another at time 41 representing the D\&D payment. Note that the neither the construction nor the D\&D is explicitly represented as a time series; this is to simplify the cash flow by converting them to single values. 


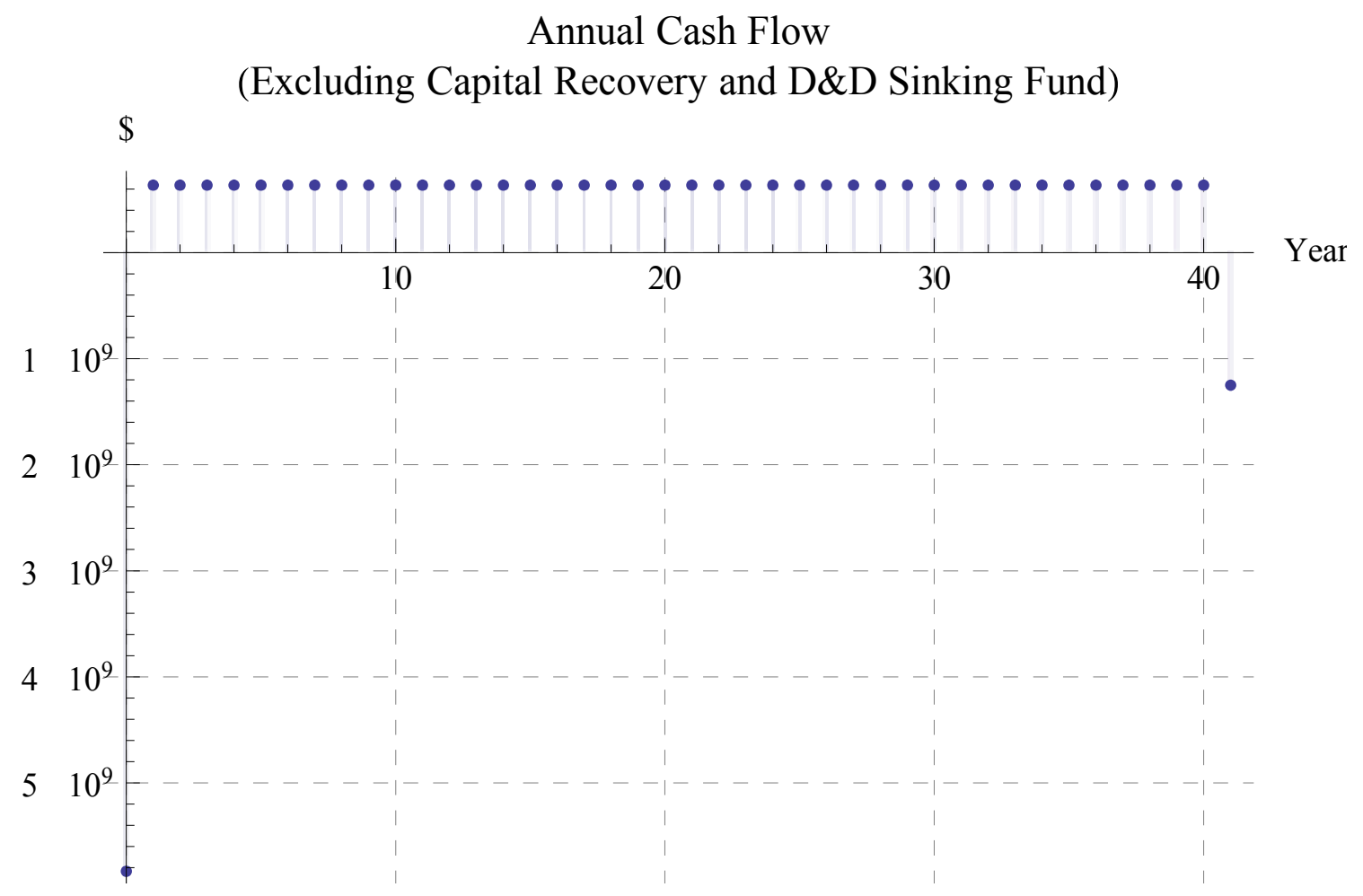

Fig. 6. Annual cash flow by year for base case.

The net annual cash flow (Fig. 6) shows the rolled-up capital cost of \$5.8 B (including interest during construction) at year 0; uniform cash flows through year 40 at $\$ 635 \mathrm{M}$; and the D\&D cost of $\$ 1.2 \mathrm{~B}$ at year 41 .

Note that the cash flow shows the capital and D\&D costs as individual flows instead of as annualized costs. This is so they can be used in an internal rate of return calculation. They will also be used to show cumulative cash flows for breakeven periods. 


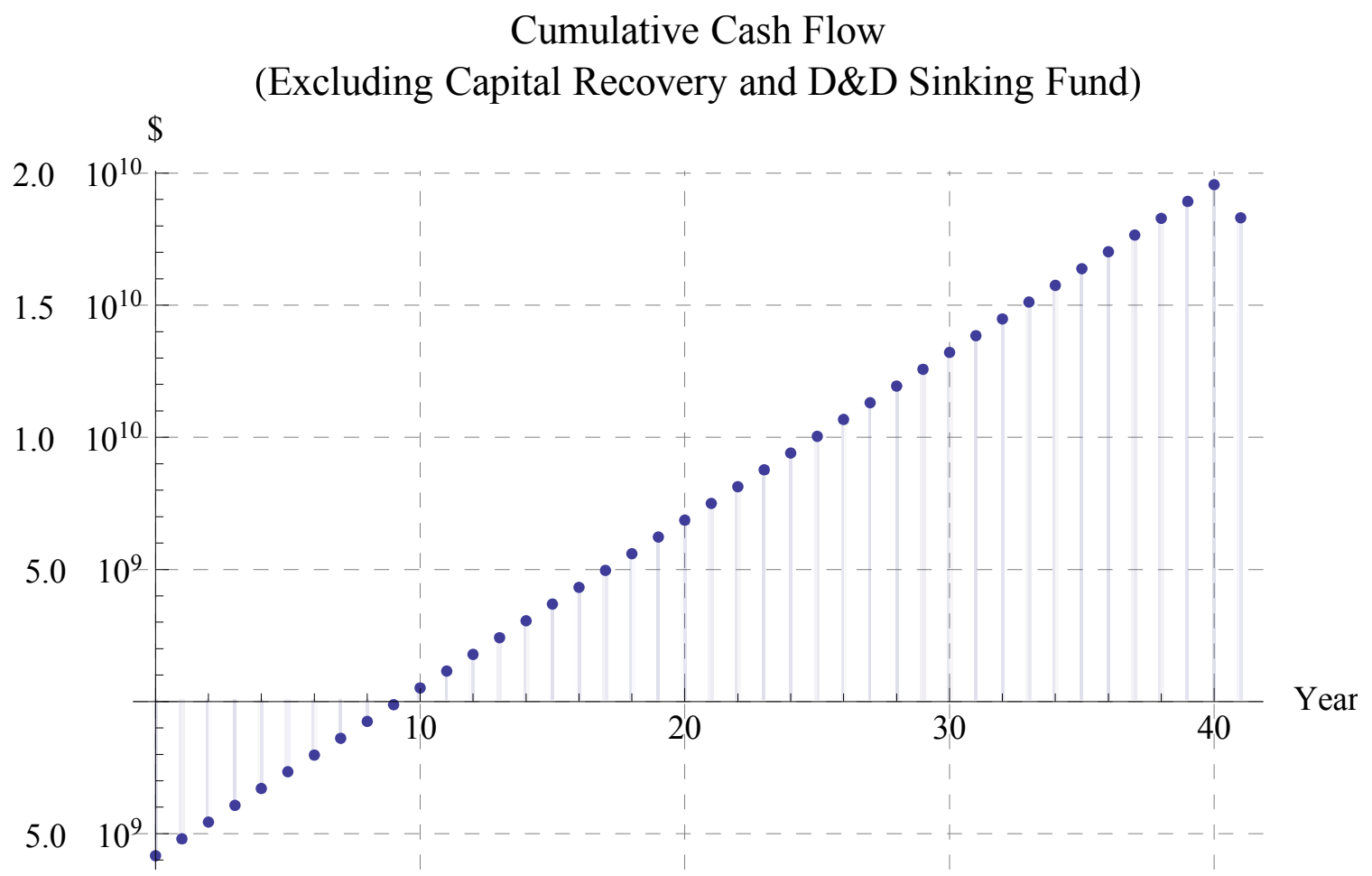

Fig. 7. Cumulative cash flow by year for base case.

Note in Fig. 7 that at $\$ 100 / \mathrm{MWh}$, the breakeven period is a little over 9 years for an undiscounted cash flow. Note also that the total value (in this case also a net present value) of the reactor is nearly $\$ 20$ B. Applying a discount rate of 3\% subtly changes the breakeven and drastically changes the net present value. Note that the $3 \%$ discount rate is not the interest charged on capital, but is a measure of the time value of money. Real discount rates will vary by project and market; this is simply used as an example calculation.

Also, note that using the NEI values increases the breakeven period. Since the production cost is fixed at $\$ 22.90 / \mathrm{MWh}$, and electricity is sold at $\$ 100 / \mathrm{MWh}$, the net annual revenue is $\$ 608 \mathrm{M}$ instead of $\$ 635 \mathrm{M}$. This increases the breakeven period to 9.6 years, a difference of $5 \%$. 


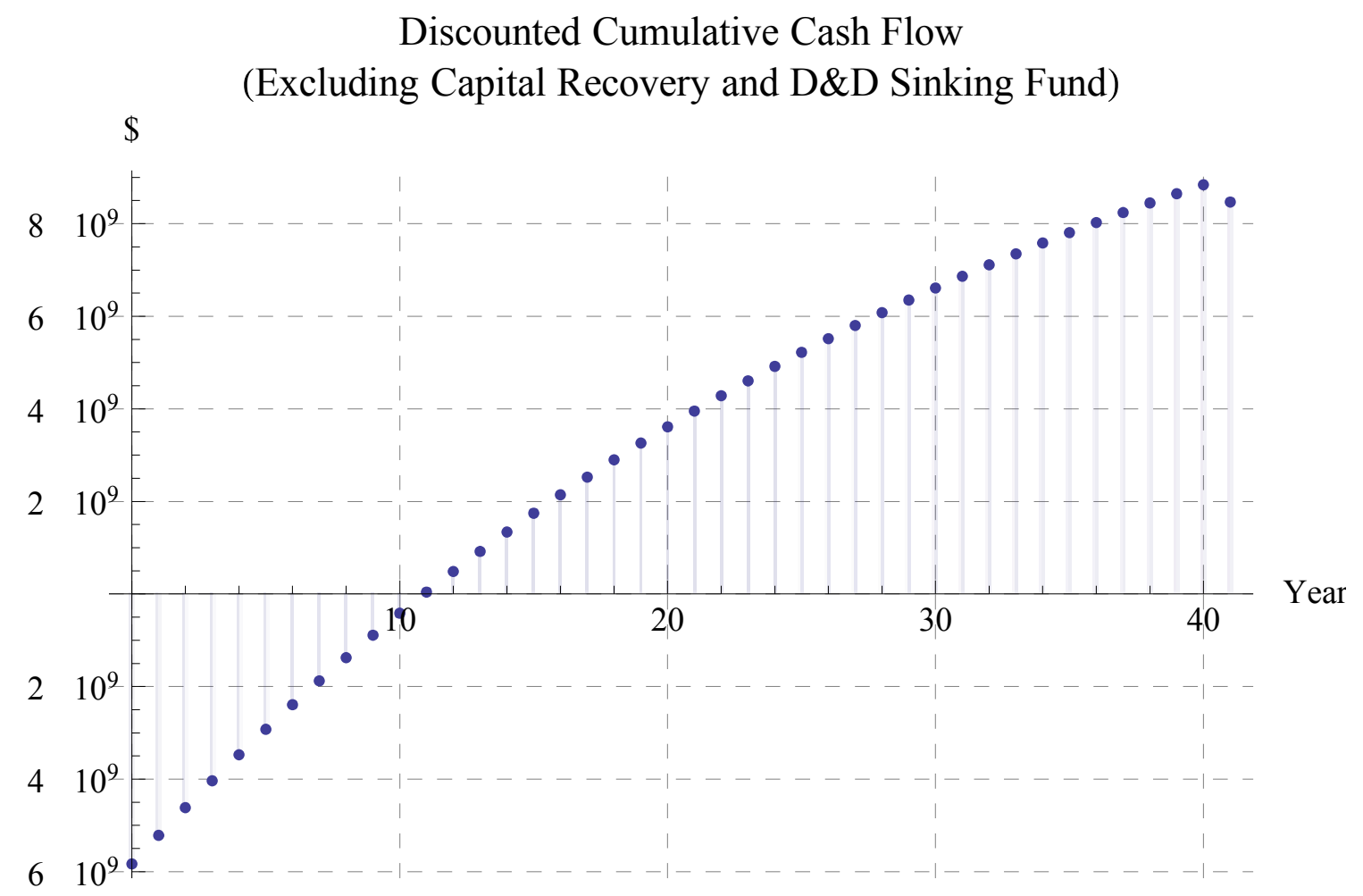

Fig. 8. Discounted cumulative cash flow by year for base case.

Now the breakeven is 11 years, but the net present value is around $\$ 8 \mathrm{~B}$-less than half the undiscounted net present value (Fig. 8). The next plot shows the results in terms of internal rate of return (IRR). 


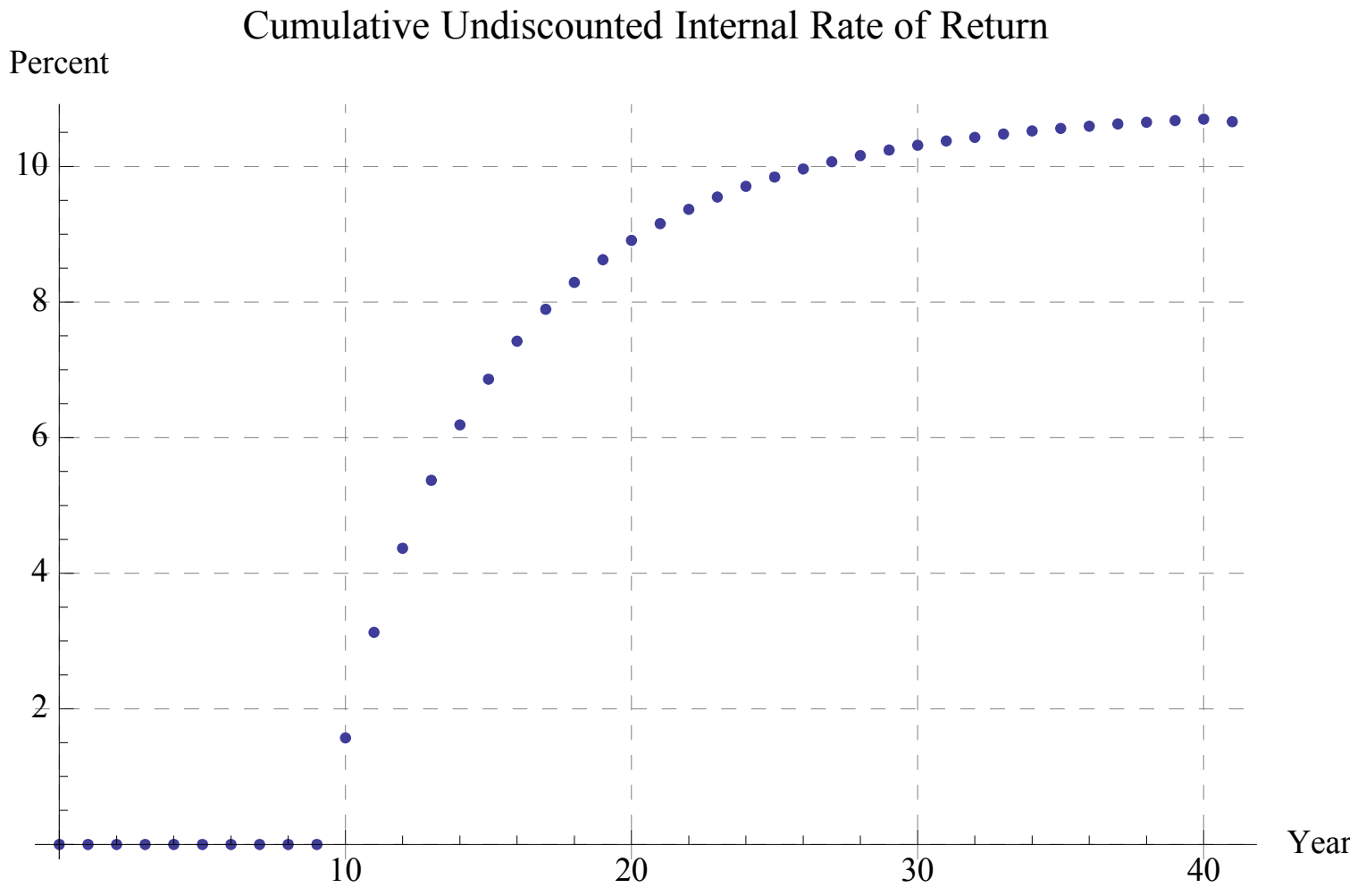

Fig. 9. Undiscounted annualized internal rate of return by year for base case.

Figure 9 shows that after 40 years, the internal rate of return is approaching an annualized $11 \%$. However, consistent with the 10-year undiscounted breakeven period, the IRR is less than 0 until year 10 , when it is still less than $2 \%$.

\subsection{THE SMR}

Now apply the same analysis to a SMR. This changes only a couple of the initial assumptions. Note that since all things are assumed to scale linearly, this makes the SMR just a smaller version of an LWR. This is obviously not universally applicable - some costs (probably most costs) will not scale linearly. The assumptions are as follows:

- $\quad 300$ MWt (bolded for contrast with the base case)

- $33.3 \%$ thermal efficiency

- $90 \%$ capacity factor (constant through life)

- 5 year construction period

- 40 year lifetime

- $\$ 5000 / \mathrm{kWe}$

- D\&D costs $25 \%$ of construction

- $3 \%$ discount rate

- $\$ 100 / \mathrm{MWh}$ market rate

- $5 \%$ interest rate during construction and payback

- $5 \%$ interest earned on D\&D sinking fund

- 40 year capital recovery (full lifetime) 
The results are identical from the perspective of levelized cost, IRR, and breakeven periods. The magnitudes of the costs and cash flows are different by a power of 10, but normalization brings the results back together.

\subsection{THE MODIFIED SMR}

Now change SMR-specific parameters slightly. Assume there is a higher specific cost in $\$ / \mathrm{kWe}$ and apply a $10 \%$ SMR premium. However, assume other costs remain linear. Assume the construction period is 3 years versus 5 years, and that the interest charged during construction is only $3 \%$. Then the assumptions are as follows:

- 300 MWt

- $33.3 \%$ thermal efficiency

- $90 \%$ capacity factor (constant through life)

- 3 year construction period

- 40 year lifetime

- $\$ 5500 / \mathbf{k W e}$

- D\&D costs $25 \%$ of construction

- $3 \%$ discount rate

- $\$ 100 / \mathrm{MWh}$ market rate

- $3 \%$ interest rate during construction and payback

- $5 \%$ interest earned on D\&D sinking fund

- 40 year capital recovery (full lifetime)

The results are striking. 


\section{Levelized Cost by Year}

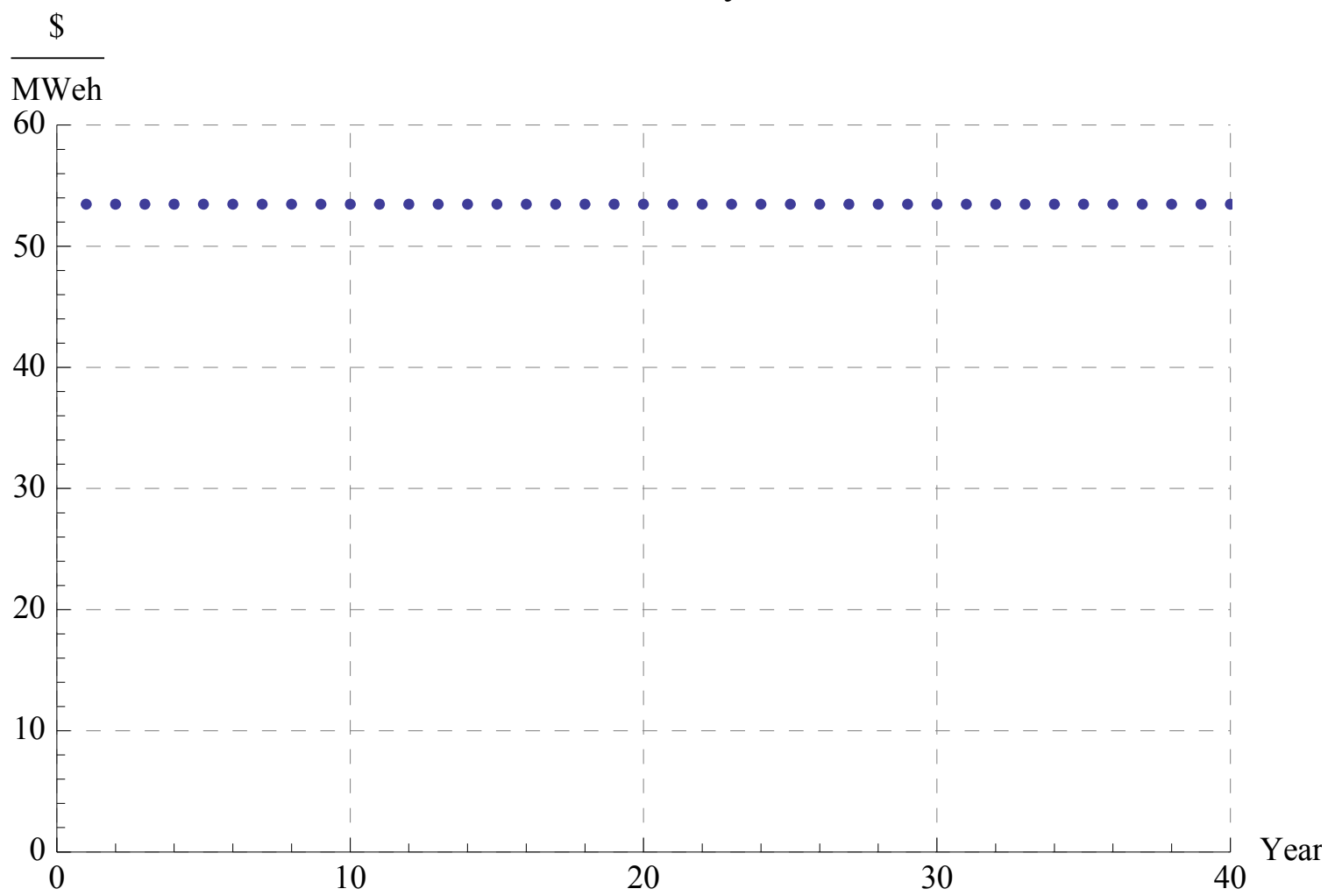

Fig. 10. Levelized cost by year for SMR.

The levelized cost (Fig. 10) is less than the previous case at $\$ 54 / \mathrm{MWh}$, even though the specific cost was higher. This is due exclusively to the $3 \%$ versus $5 \%$ interest charged during construction and payback.

The undiscounted breakeven period is still around 10 years (Fig. 11), and the discounted breakeven period is still around 11 years (Fig. 12). 


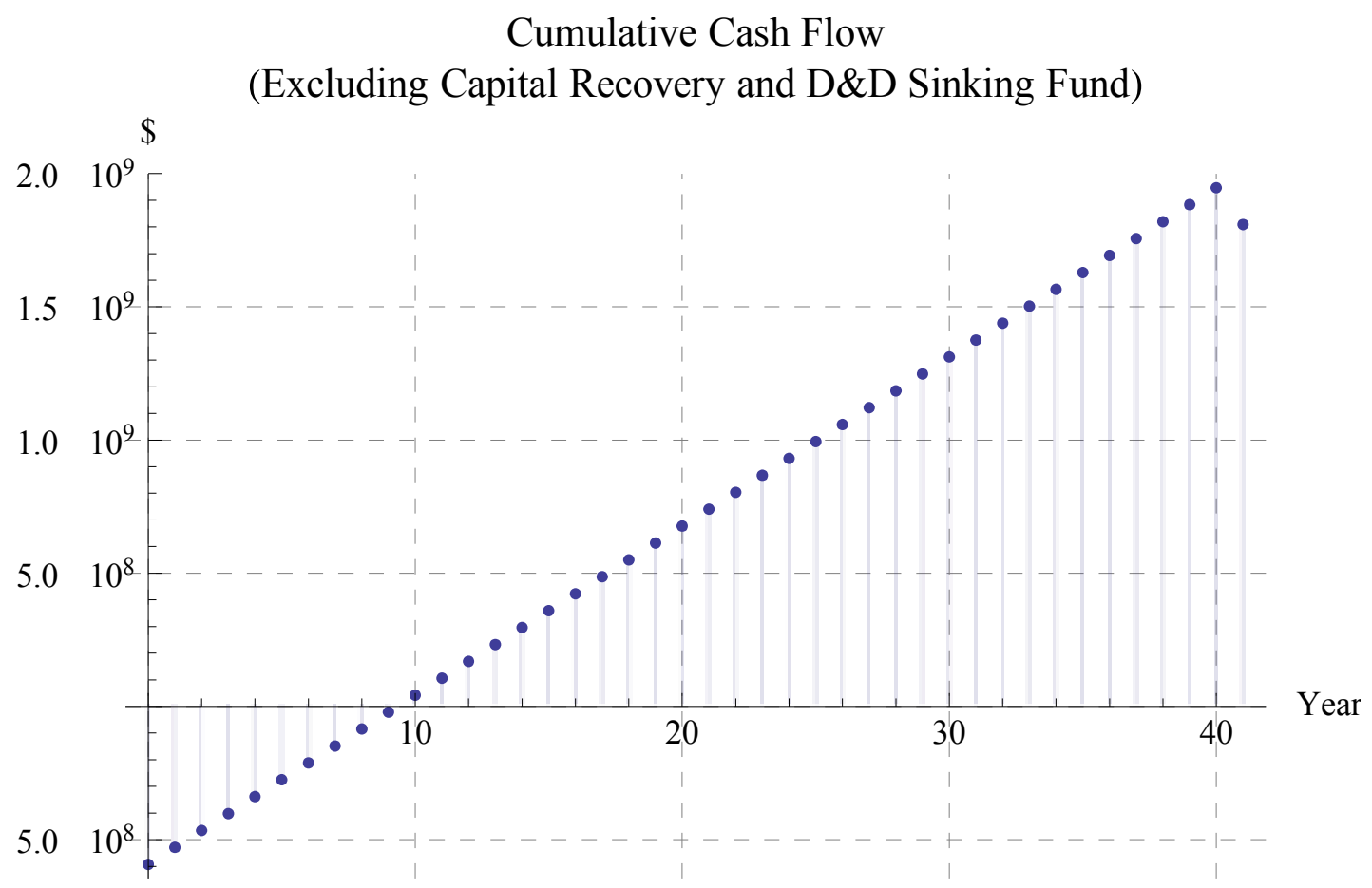

Fig. 11. Cumulative cash flow by year for SMR.

Discounted Cumulative Cash Flow

(Excluding Capital Recovery and D\&D Sinking Fund)

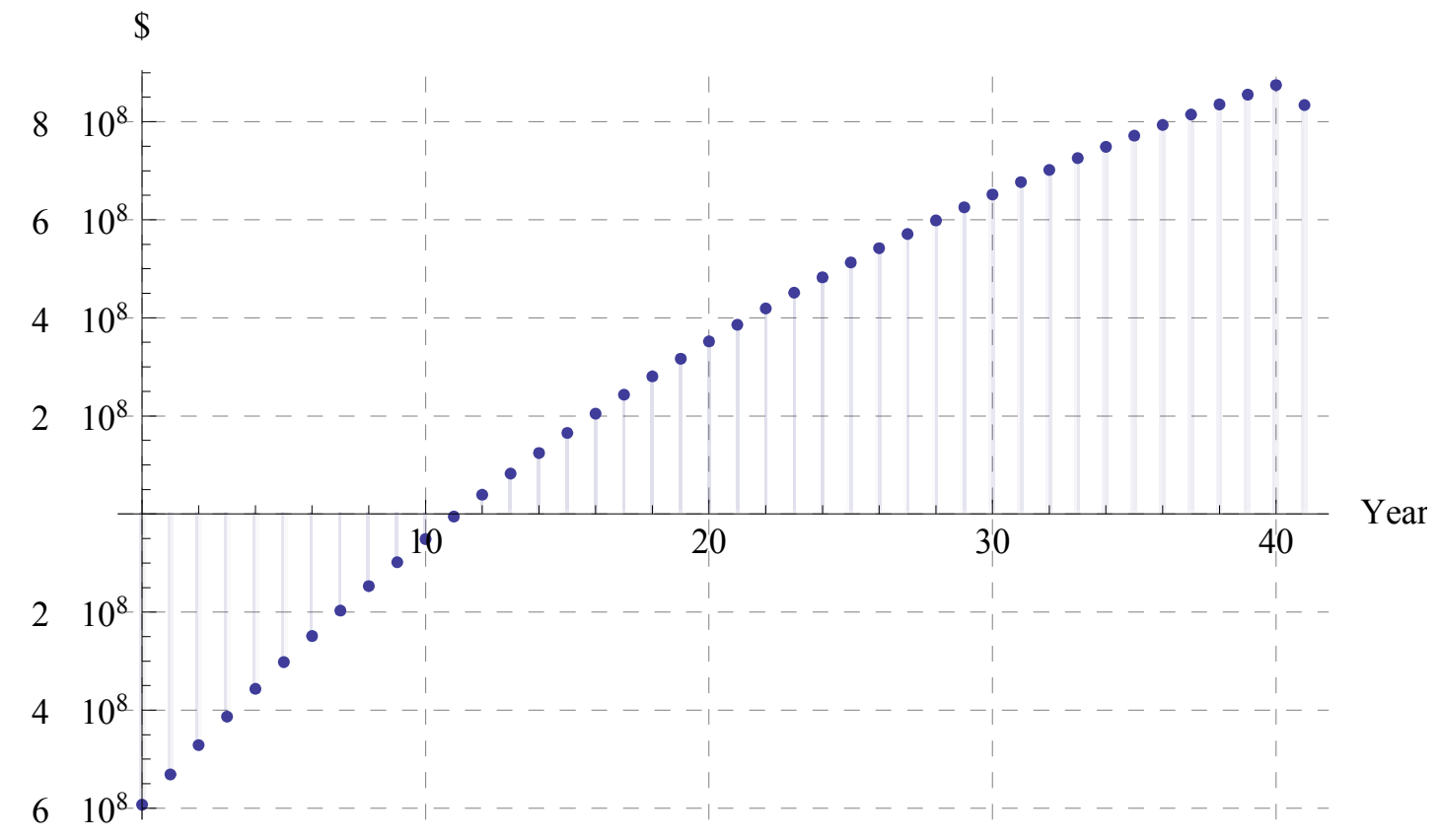

Fig. 12. Discounted cumulative cash flow by year for SMR.

In an interesting turn, the undiscounted IRR is slightly less than the undiscounted IRR for the previous case (Fig. 13). 


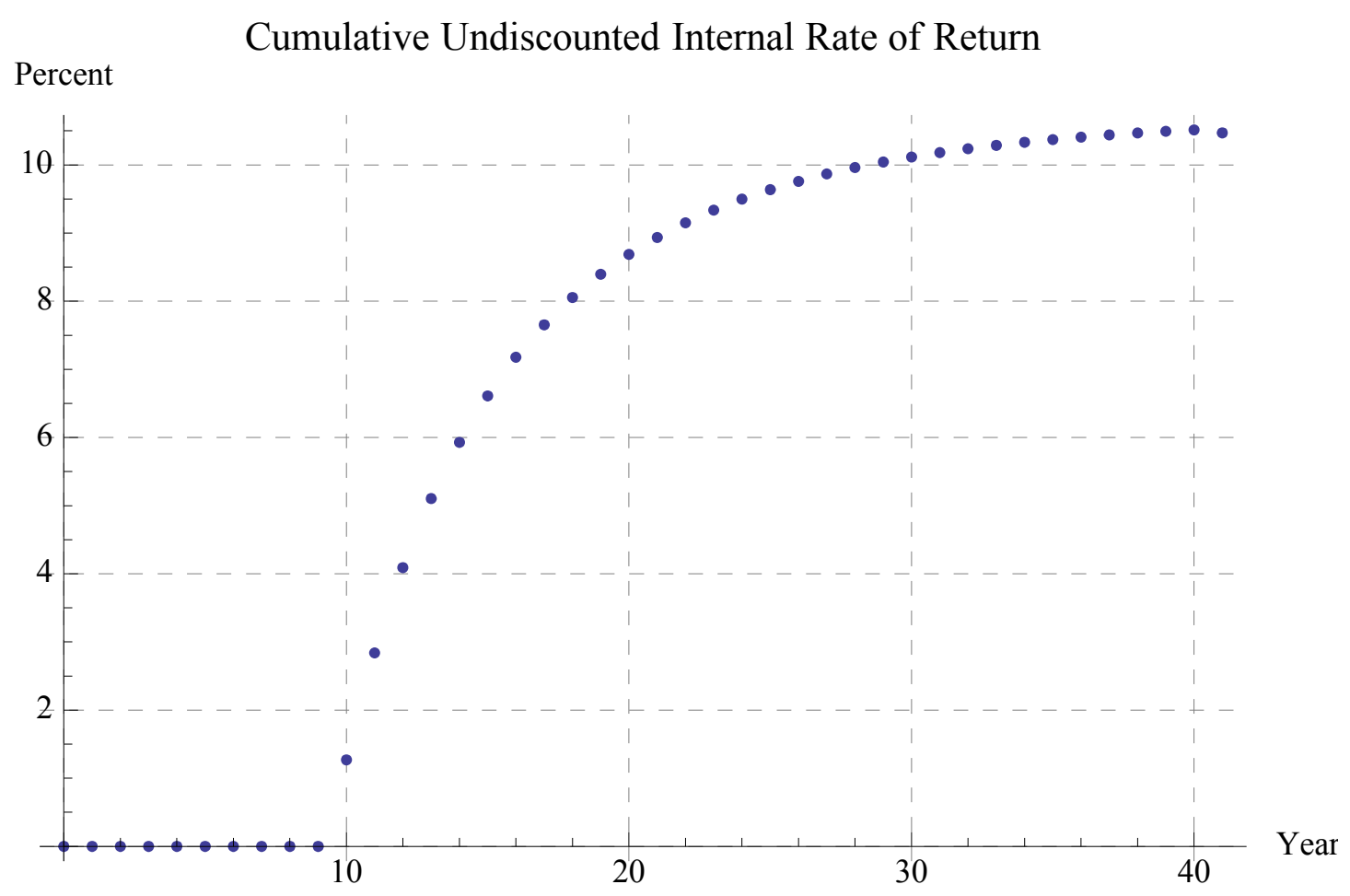

Fig. 13. Undiscounted annualized internal rate of return by year for SMR.

In effect, this case demonstrates that from an investor perspective, an SMR may not be the most attractive nuclear option, although a customer may appreciate the lower levelized cost.

However, this is for a single SMR unit. Adding a second unit changes the system dynamics.

\subsection{THE MULTI-UNIT SMR}

Earlier a set of assumptions was given: $60 \%$ of the initial unit cost is construction and $40 \%$ is nuclear reactor and power conversion. For the second unit, the construction cost is half the construction cost of the first. This does not reflect a learning curve; rather, this reflects that a large amount of one-time construction was included in the total construction cost of the first unit. For example, the second unit does not require a second parking lot, office building, cafeteria, and security fence. Finally, assume the two units are built sequentially with a 3 year delay between them. Using those assumptions, the analysis yields these figures. 


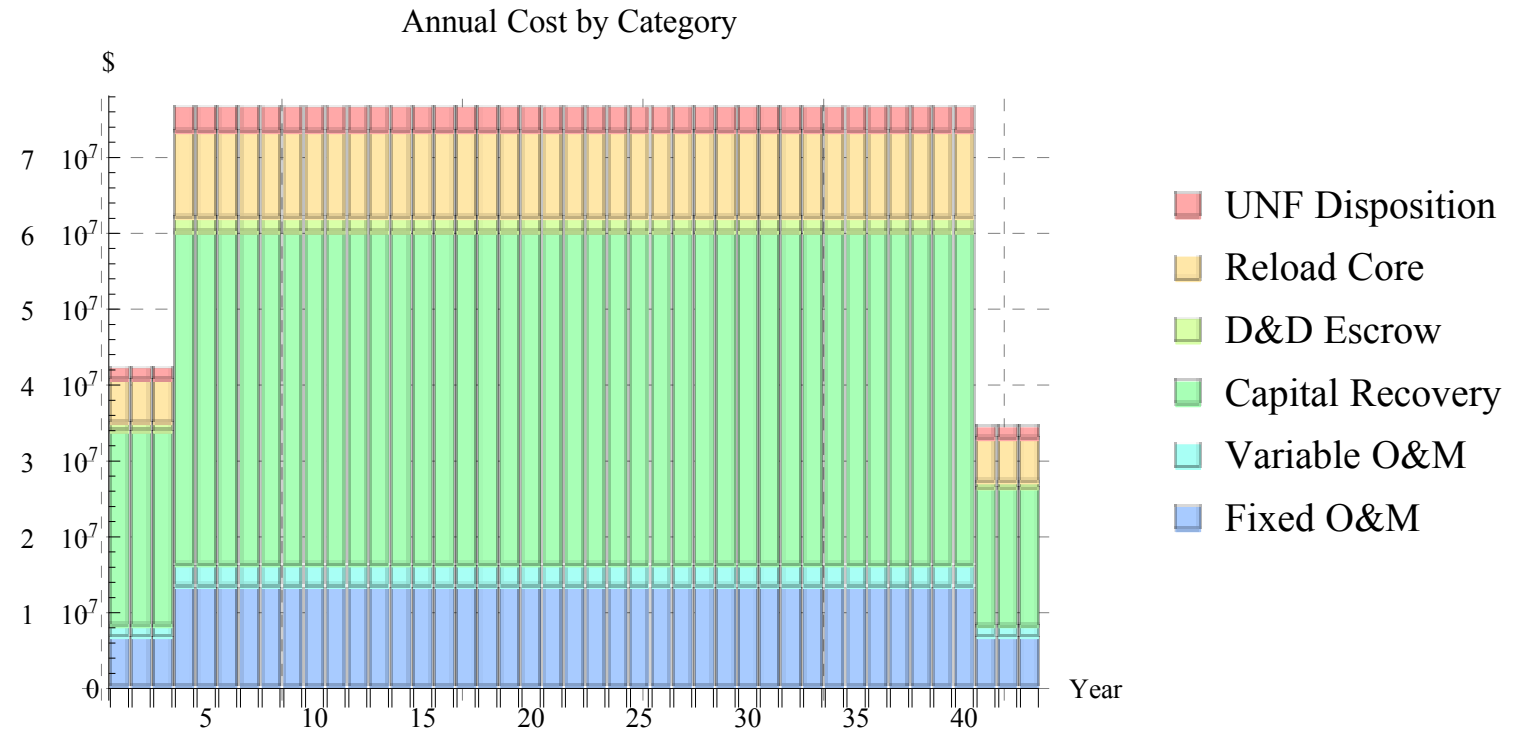

Fig. 14. Annual cost by category by year for multi-unit SMR.

The annual costs (Fig. 14) for the first 3 years are solely driven by the first unit. After the second unit comes online, the annual costs are the sum of the two units. Note that this does not take credit for shared O\&M costs. When the first unit shuts down after year 40 , the annual costs then only reflect the second unit; these costs are significantly less than the corresponding costs for the first unit. This difference is due to the smaller capital recovery.

The levelized cost by year (Fig. 15) shows the same results.

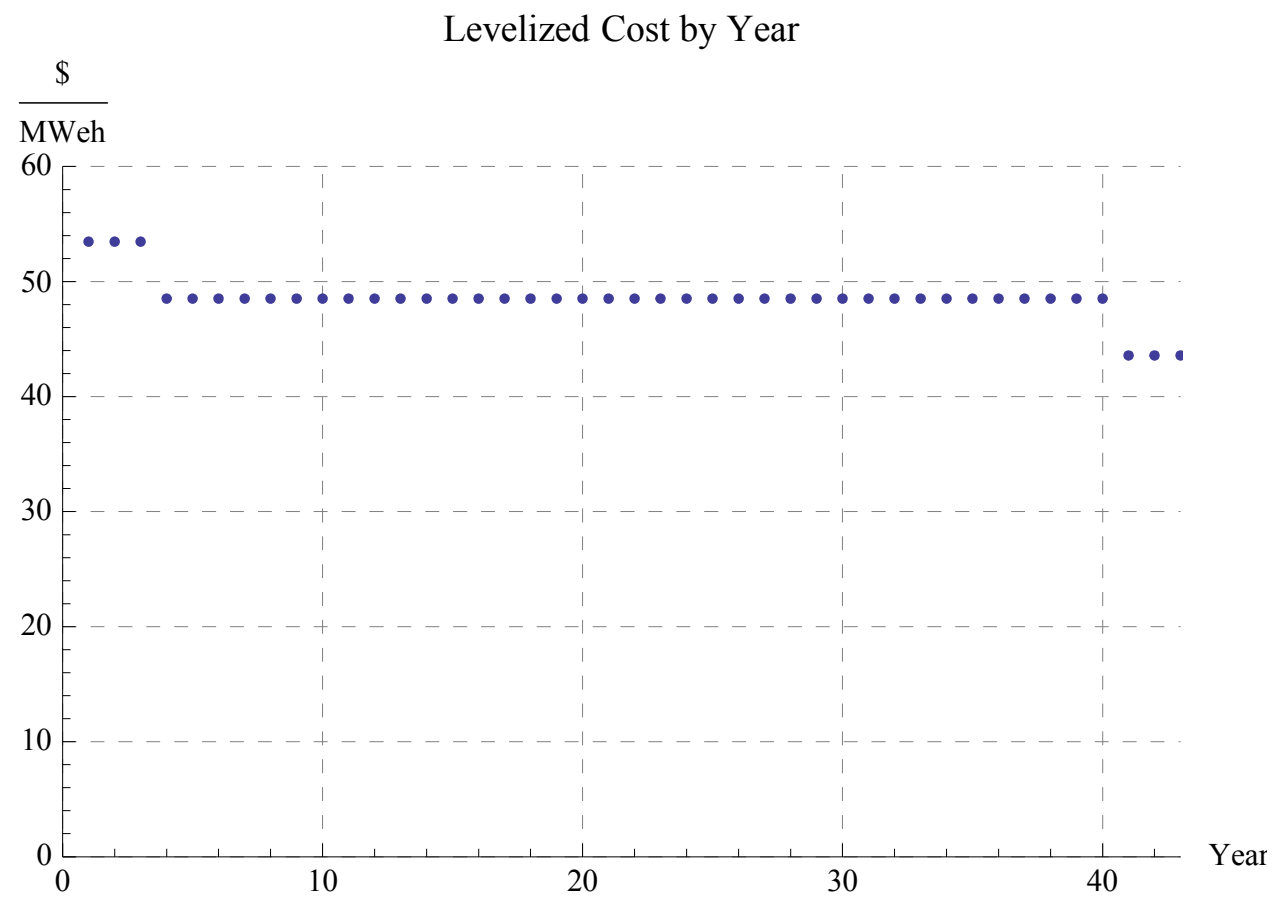

Fig. 15. Levelized cost by year for multi-unit SMR. 
The construction of the second unit lowers the overall levelized cost for the site.

The cash flow diagram (Fig. 16) for the site also gives a similar result.

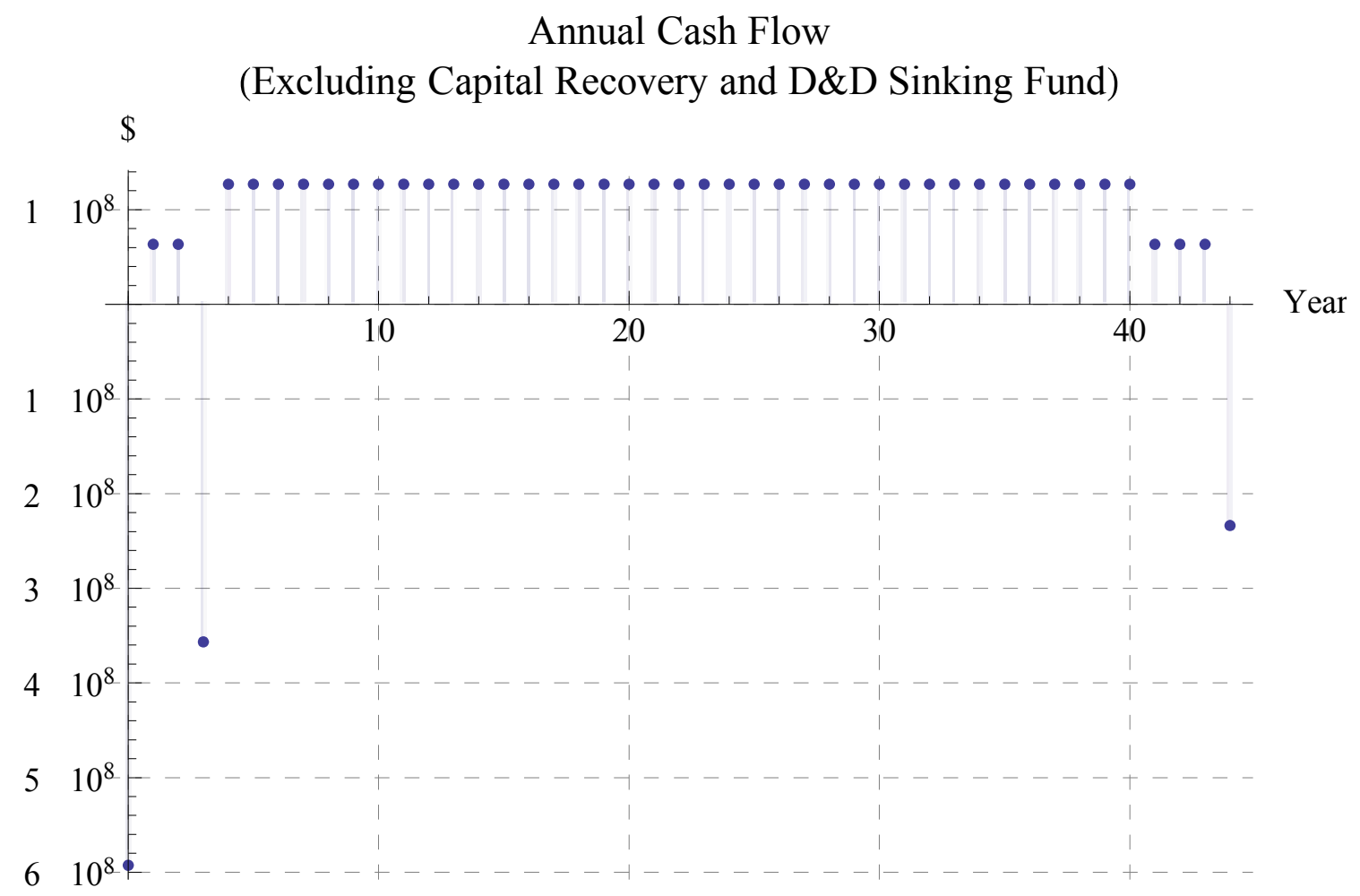

Fig. 16. Annual cash flow by year for multi-unit SMR.

Further analysis on the undiscounted cash flow diagram (Fig. 17) shows an interesting result. 


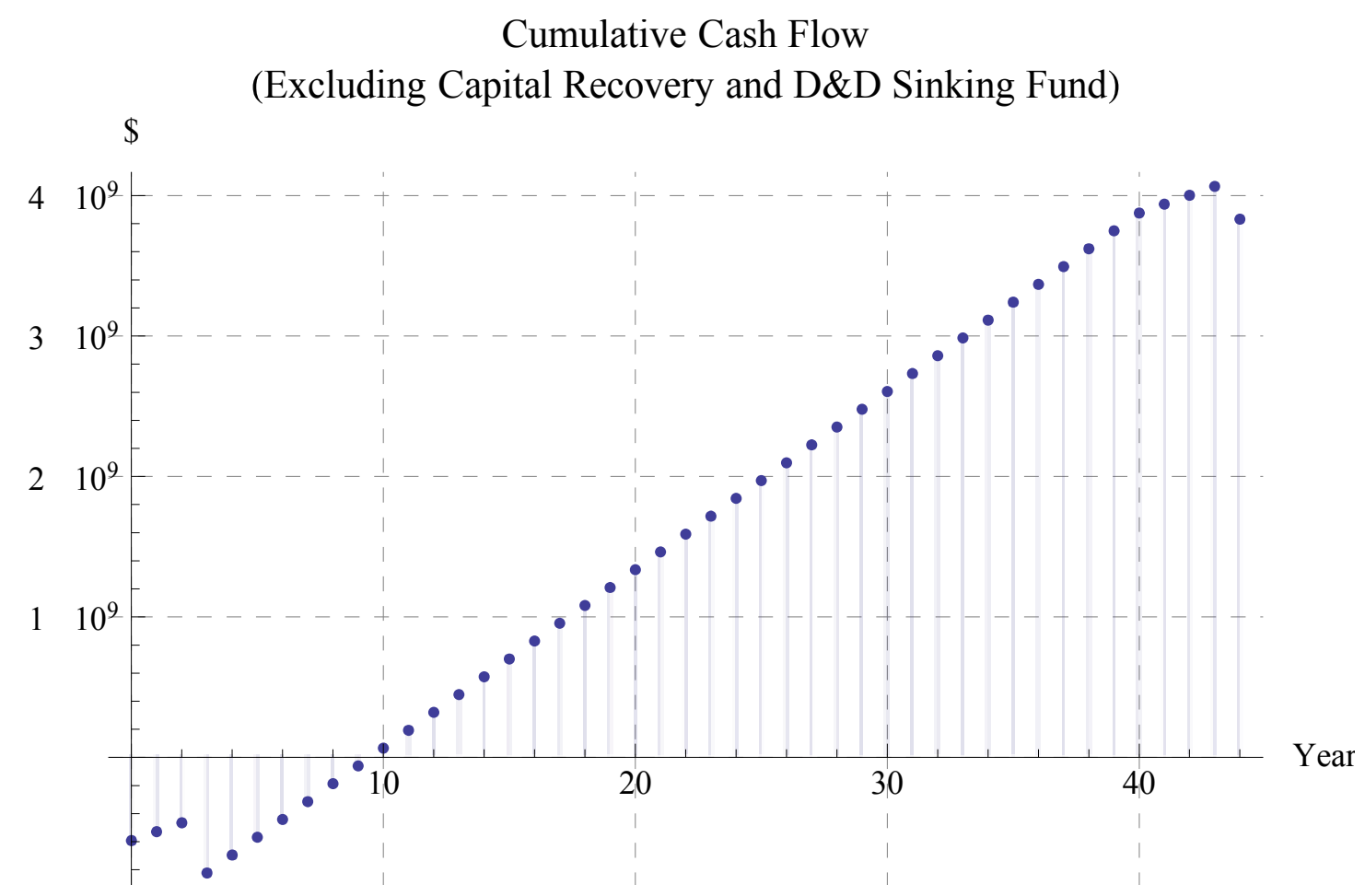

Fig. 17. Cumulative cash flow by year for multi-unit SMR.

The breakeven period for building a second unit at the site is still around 10 years. The maximum negative cumulative cash flow is around $\$ 800 \mathrm{M}$ versus $\$ 600 \mathrm{M}$ for the single unit (Fig. 18).

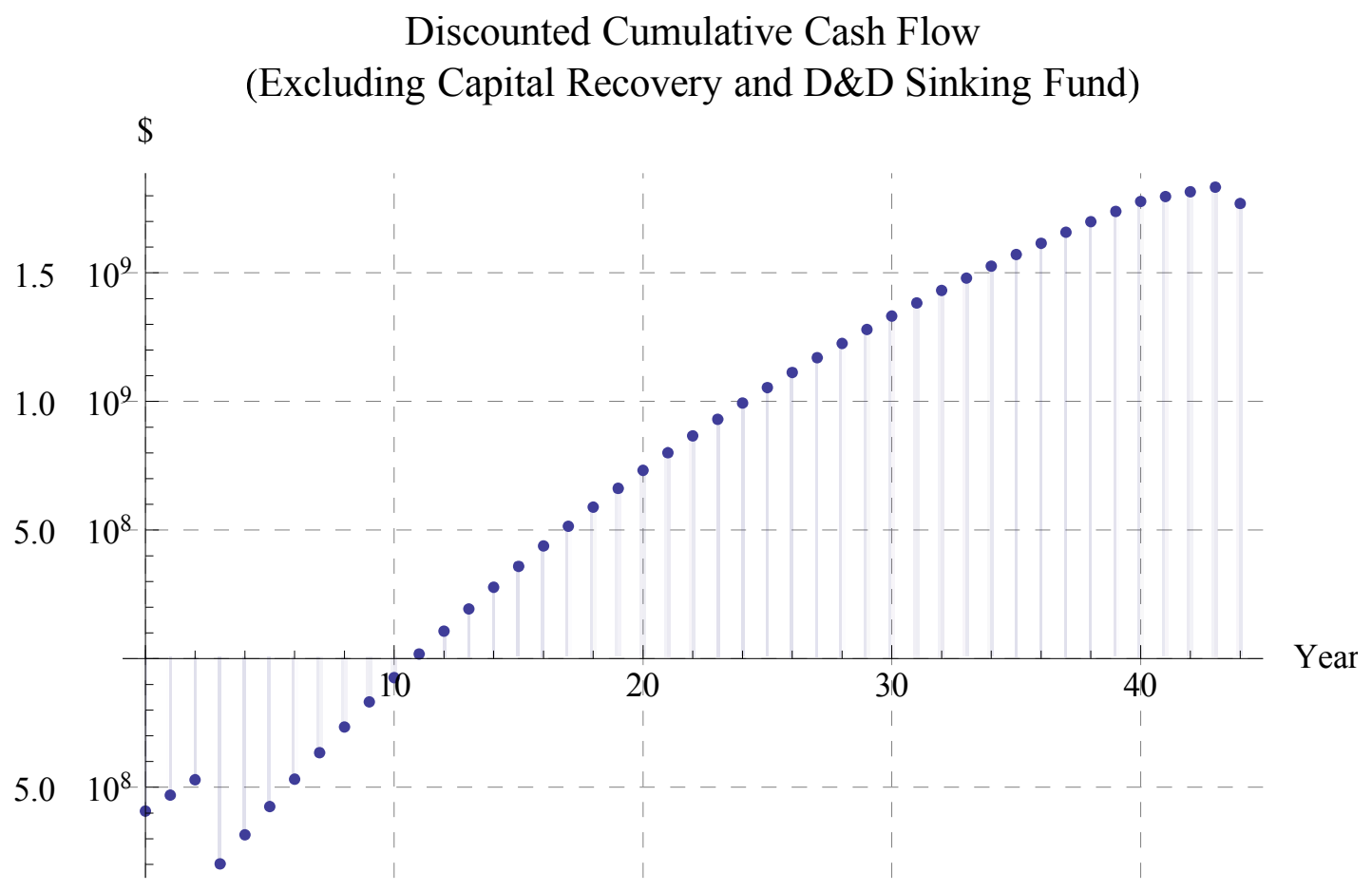

Fig. 18. Discounted cumulative cash flow by year for multi-unit SMR. 
The discounted net present value for the two-unit site is greater than $\$ 1.8 \mathrm{~B}$ compared to less than $\$ 900 \mathrm{M}$ for the single-unit site. Doubling the site generating capacity more than doubles the value of the site.

Finally, the IRR for the site is approximately $12 \%$ after 40 years, and exceeds $10 \%$ after 20 years (Fig. 19). The single-unit SMR (Section 3.3) case did not reach 10\% until 30 years of operation.

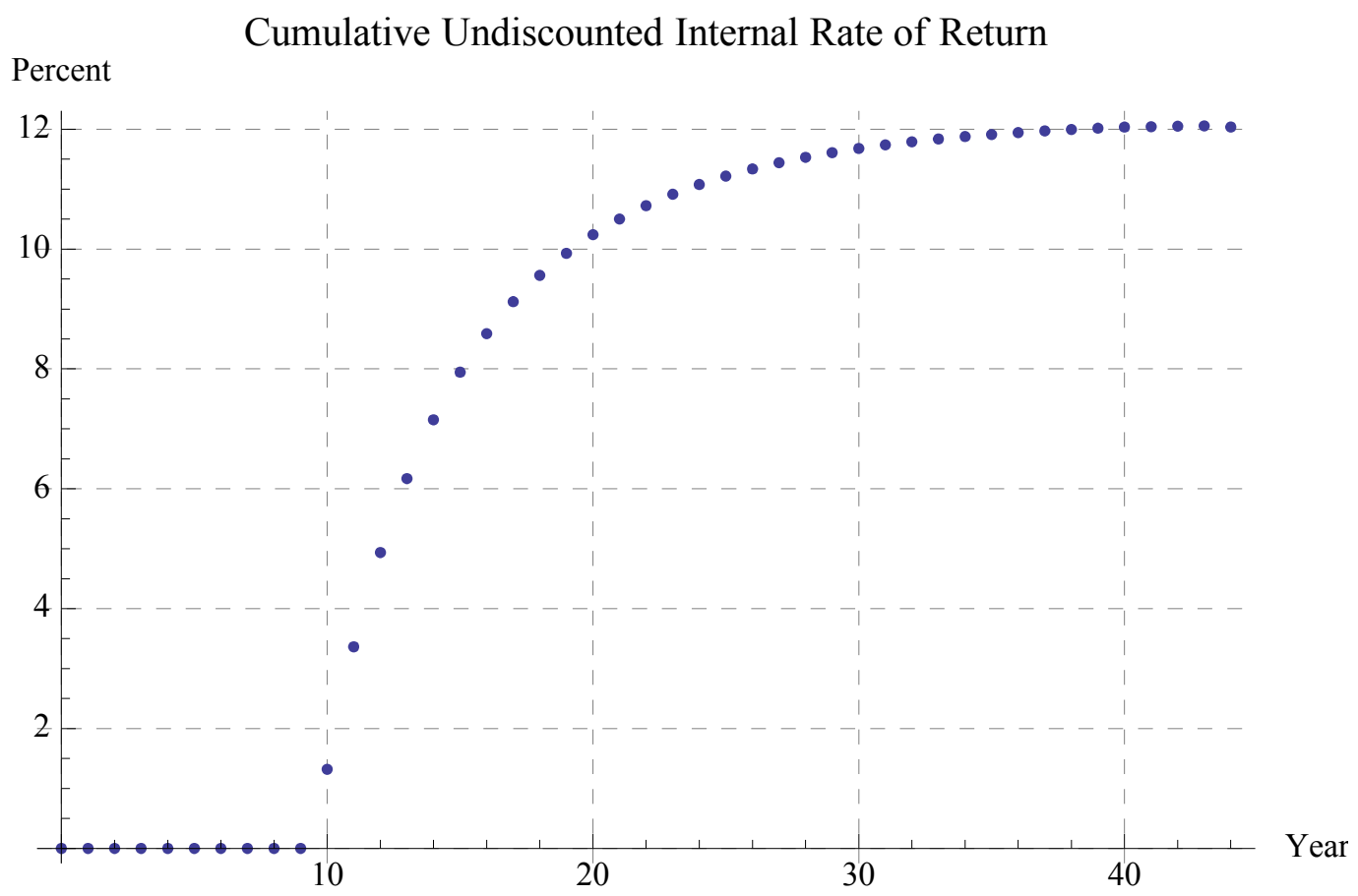

Fig. 19. Undiscounted annualized internal rate of return by year for multi-unit SMR.

\subsection{THE EFFECT OF CAPACITY FACTOR}

The final modified variable to include is the capacity factor. For this example, assume the capacity factor starts at $60 \%$ in the first year and has a 5 year ascent to $90 \%$. Thus, the assumptions are as follows:

- $300 \mathrm{MWt}$

- $33.3 \%$ thermal efficiency

- $90 \%$ capacity factor with 5 year ramp from $60 \%$

- 3 year construction period

- 40 year lifetime

- $\$ 5500 / \mathrm{kWe}$

- D\&D costs $25 \%$ of construction

- $3 \%$ discount rate

- $\$ 100 / \mathrm{MWh}$ market rate

- $3 \%$ interest rate during construction and payback

- $5 \%$ interest earned on D\&D sinking fund

- 40 year capital recovery (full lifetime) 
The result of changing the capacity factor is best shown by examining the net present value and IRR figures (Figs. 20 and 21).

Discounted Cumulative Cash Flow

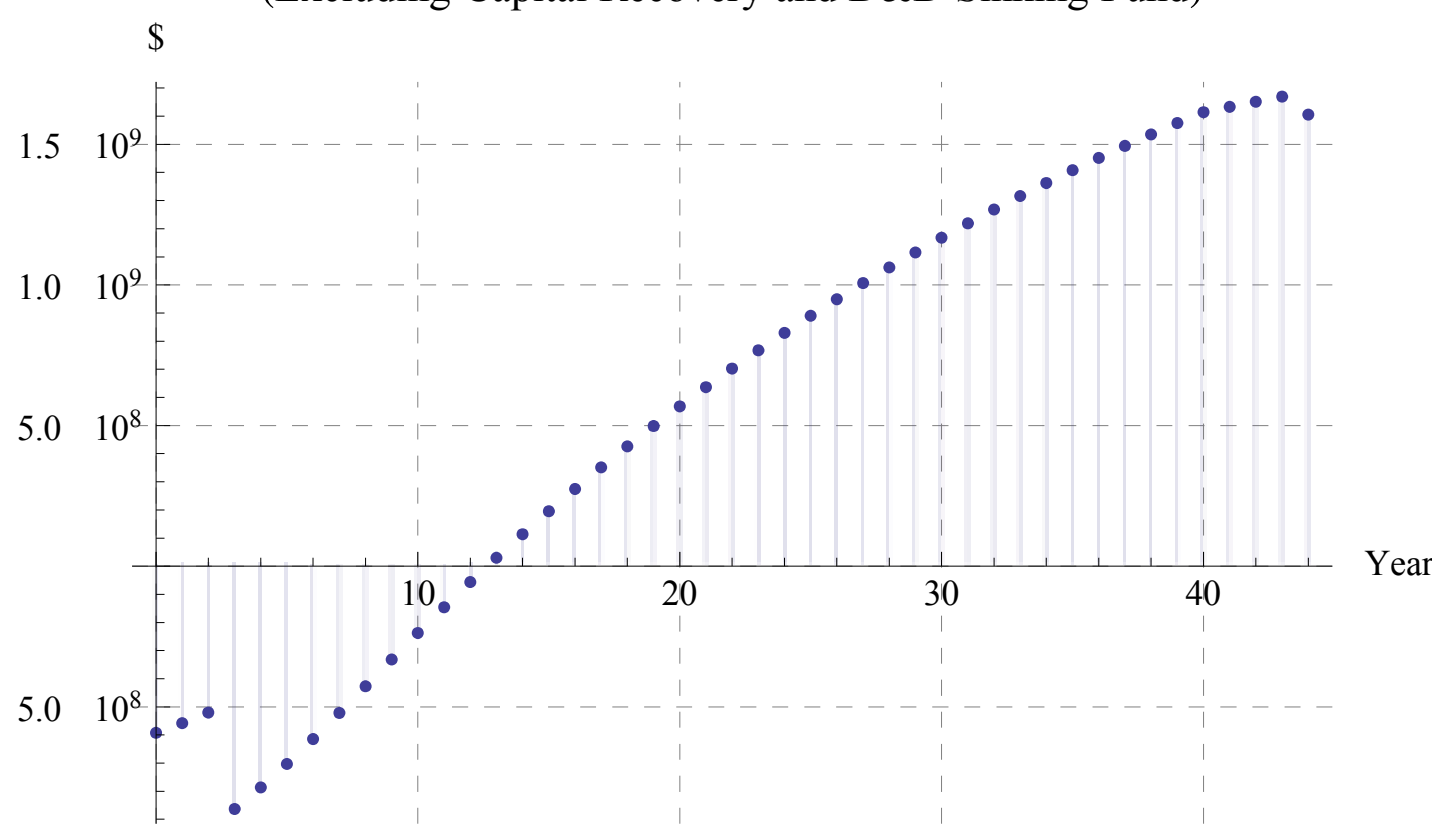

Fig. 20. Ramping capacity factor effect on multi-unit SMR discounted cash flow.

The net present value decreased to $\$ 1.7 \mathrm{~B}$ from $\$ 1.8 \mathrm{~B}-\mathrm{a} 5.6 \%$ loss.

Percent

Cumulative Undiscounted Internal Rate of Return

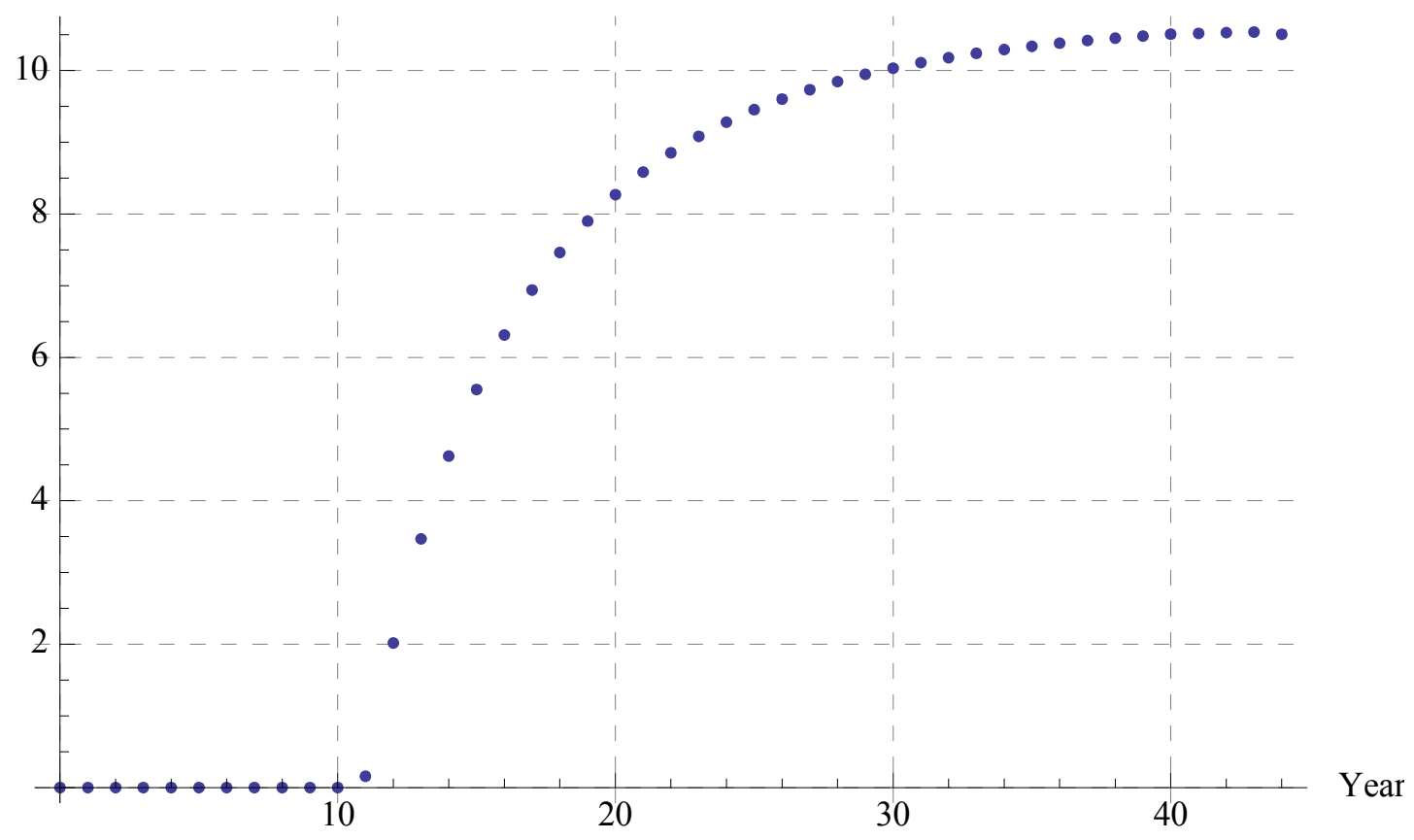

Fig. 21. Ramping capacity factor effect on multi-unit SMR internal rate of return. 
By changing the assumed capacity factor, the IRR decreased from $12 \%$ to $10.5 \%$.

\subsection{MARKET EFFECTS}

The previous cases used $\$ 100 / \mathrm{MWh}$ as the market rate for selling the electricity. This reflects the average retail rate of electricity in the United States in 2012. If the market rate is set as the wholesale rate-less than \$50/MWh [6] — the analysis changes drastically (Fig. 22).

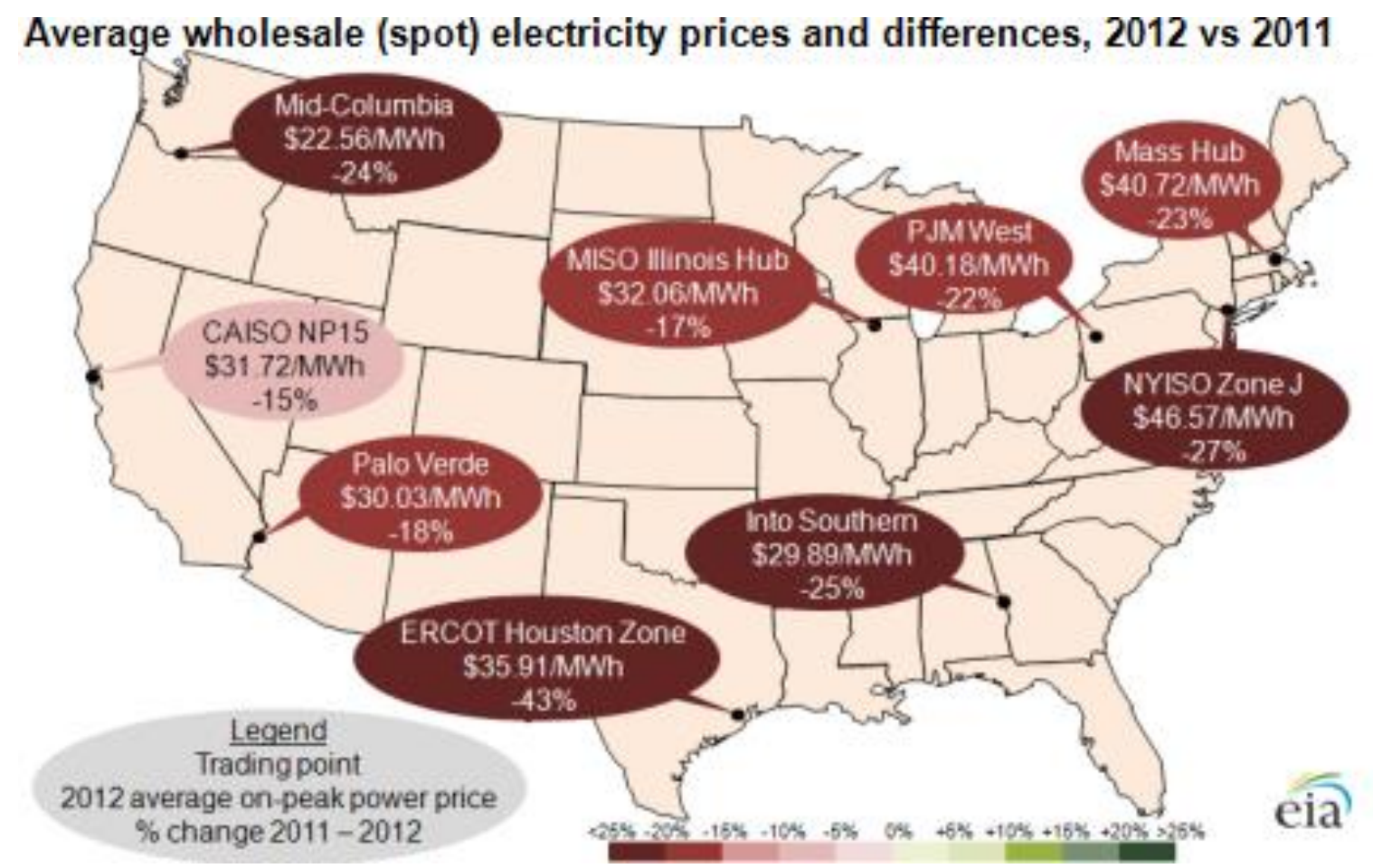

Fig. 22. Average wholesale spot prices [5]

Using the $\$ 50 / \mathrm{MWh}$ estimate, the assumptions are as follows:

- 300 MWt

- $33.3 \%$ thermal efficiency

- $\quad 90 \%$ capacity factor with 5 year ramp from $60 \%$

- 3 year construction period

- 40 year lifetime

- $\$ 5500 / \mathbf{k W e}$

- D\&D costs $25 \%$ of construction

- $3 \%$ discount rate

- $\$ 50 / M W h$ market rate

- $3 \%$ interest rate during construction and payback

- $5 \%$ interest earned on D\&D sinking fund 
Obviously, halving the market rate halves the revenue (Fig. 23).

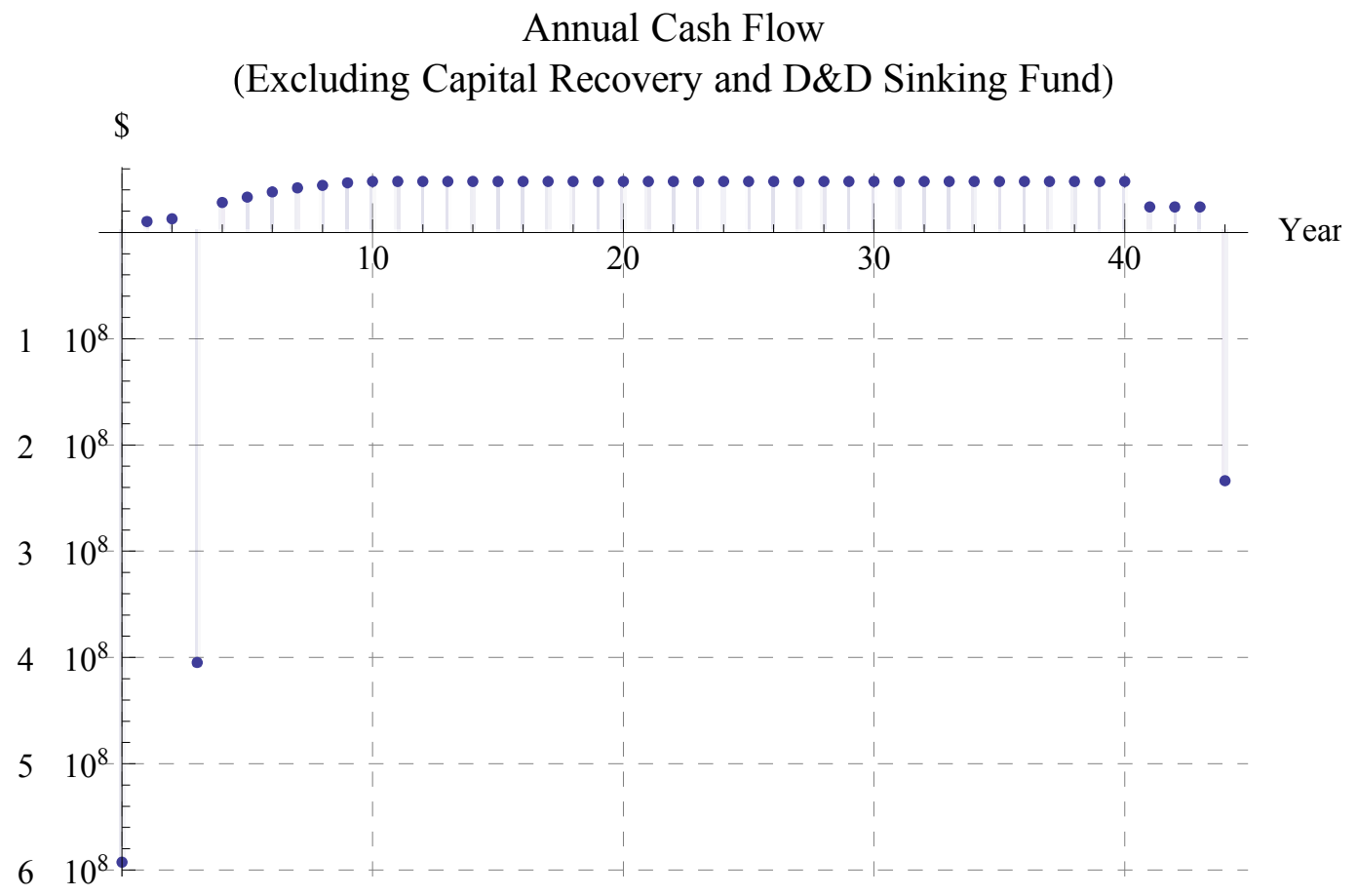

Fig. 23. Market rate effects on multi-unit SMR annual cash flow.

Decreasing the revenue affects the entire investment (Fig. 24).

Discounted Cumulative Cash Flow (Excluding Capital Recovery and D\&D Sinking Fund)

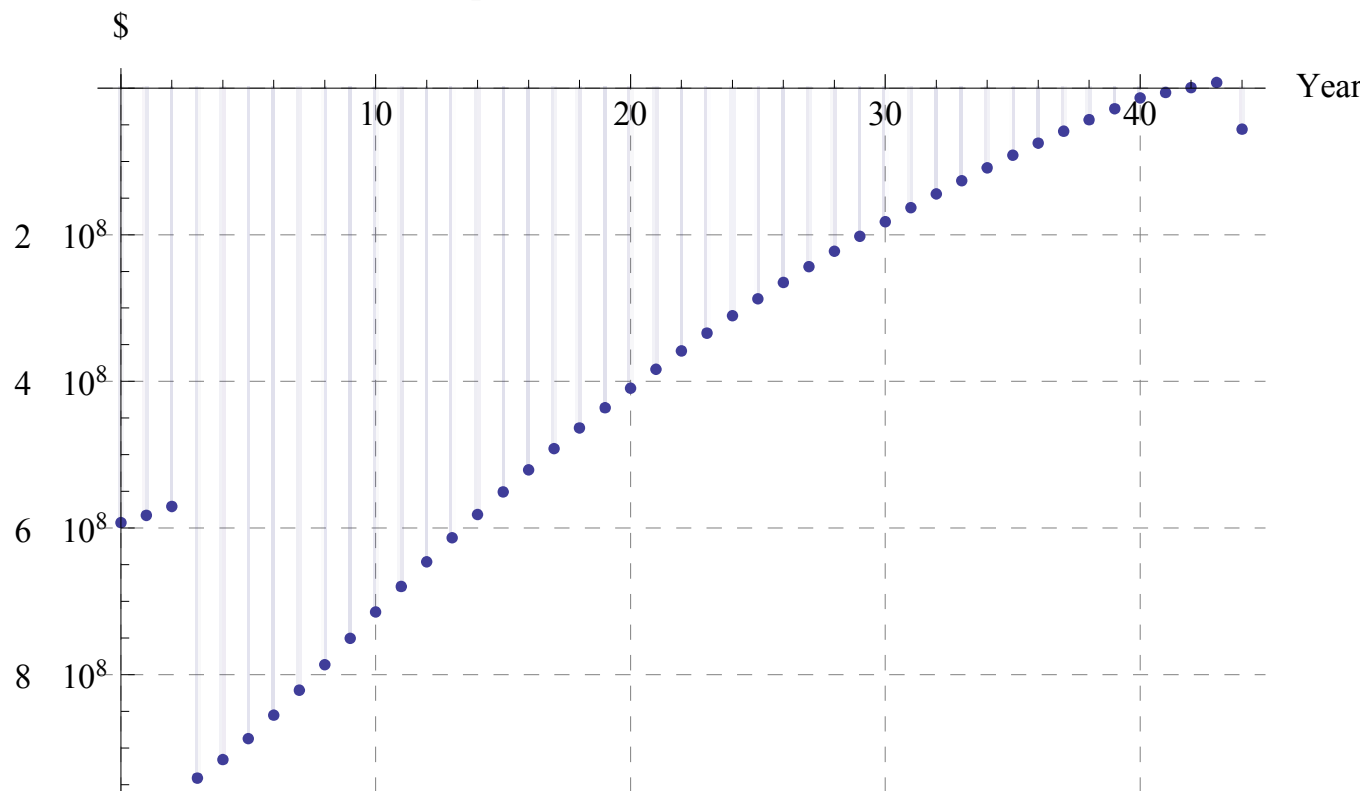

Fig. 24. Market rate effects on multi-unit SMR discounted cumulative cash flow. 
The discounted breakeven period is now the entire operational lifetime of the plant, and the inclusion of $\mathrm{D} \& \mathrm{D}$ costs brings the discounted net present value to a loss of $\$ 500 \mathrm{M}$.

However, the \$50/MWh reflects current prices; the first SMRs would likely come online in the 2020 time frame. Thus, the more appropriate market prices for analysis are the market prices likely to be seen in 2020.

Over the last 20 years, the retail price of electricity has risen nearly monotonically.

\section{Historical US Electricity Price}

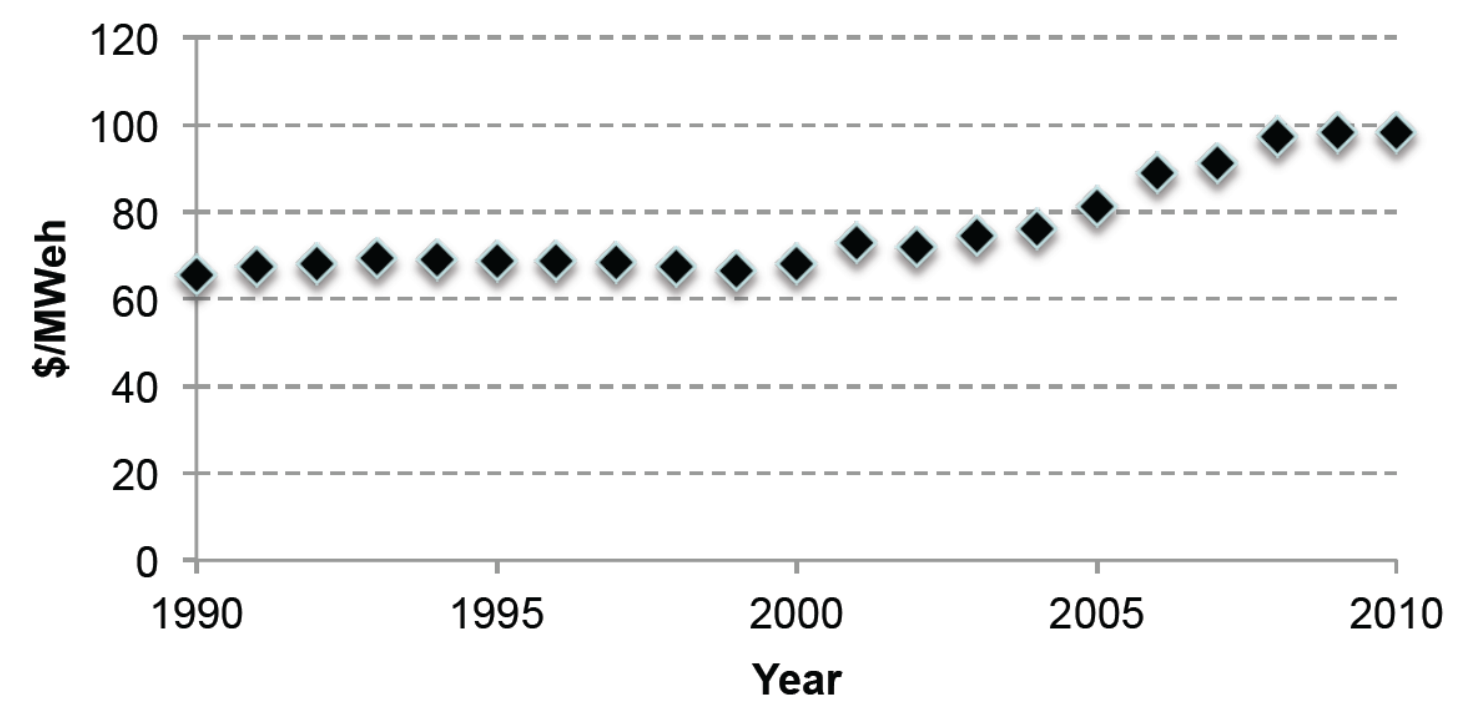

Fig. 25. Historical US retail electricity price.

The last 10 years have shown an approximately 50\% increase in the retail price of electricity [7]. Assuming a similar rise in the next 10 years, and assuming the same trend holds for wholesale prices, this yields a $\$ 75 / \mathrm{MWh}$ wholesale price. Then the assumptions are as follows:

- 300 MWt

- $33.3 \%$ thermal efficiency

- $\quad 90 \%$ capacity factor with 5 year ramp from $60 \%$

- 3 year construction period

- 40 year lifetime

- $\quad \$ 5500 / \mathbf{k W e}$

- D\&D costs $25 \%$ of construction

- $3 \%$ discount rate

- $\$ 75 / \mathbf{M W h}$ market rate

- $3 \%$ interest rate during construction and payback

- $5 \%$ interest earned on D\&D sinking fund 
This shifts the analysis favorably back toward SMR deployment (Fig. 26).

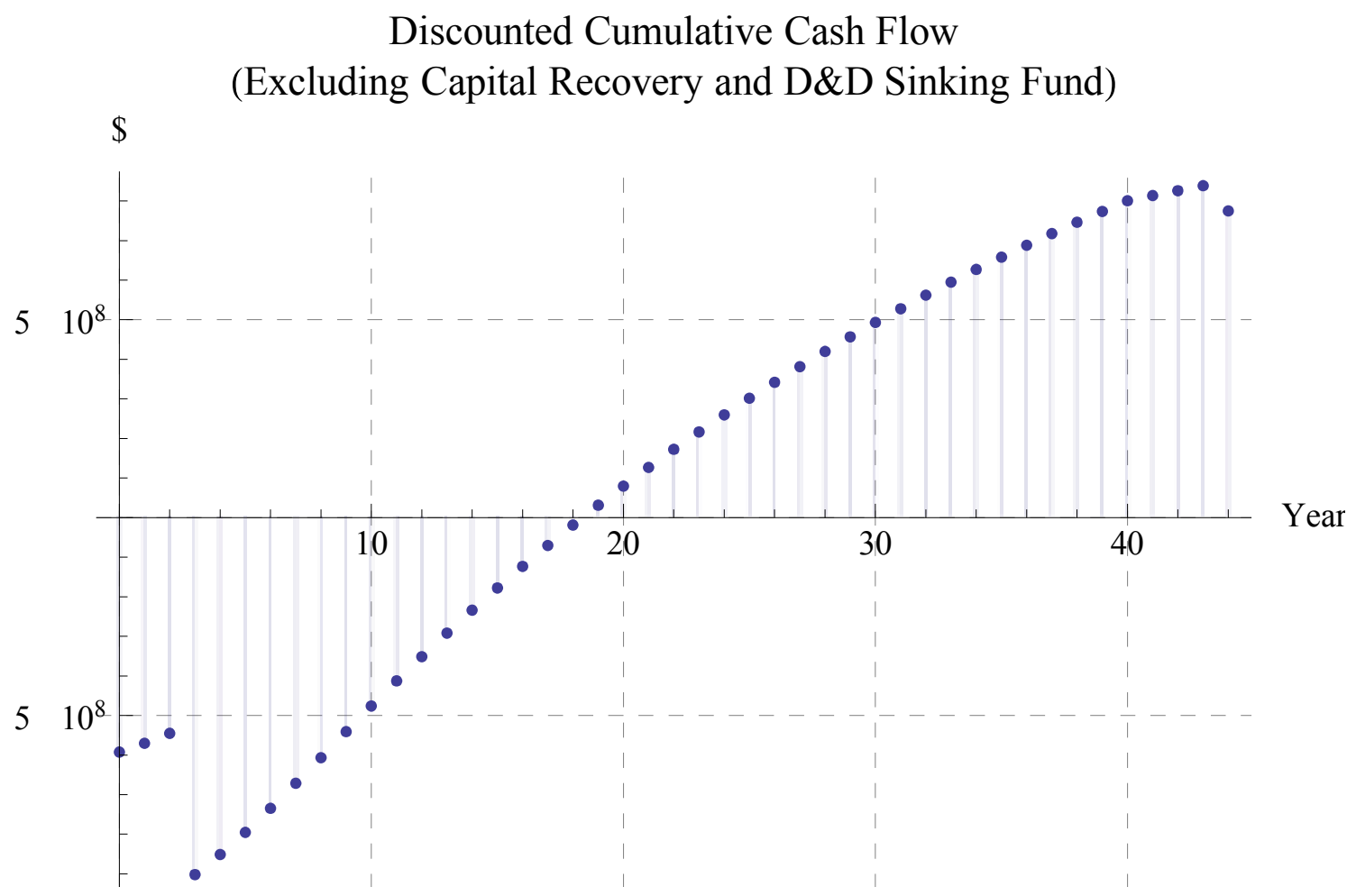

Fig. 26. Future market rate effects on multi-unit SMR discounted cumulative cash flow.

The discounted breakeven period is now 18 years, and the discounted net present value is now $\$ 700$ M (Fig. 27). 


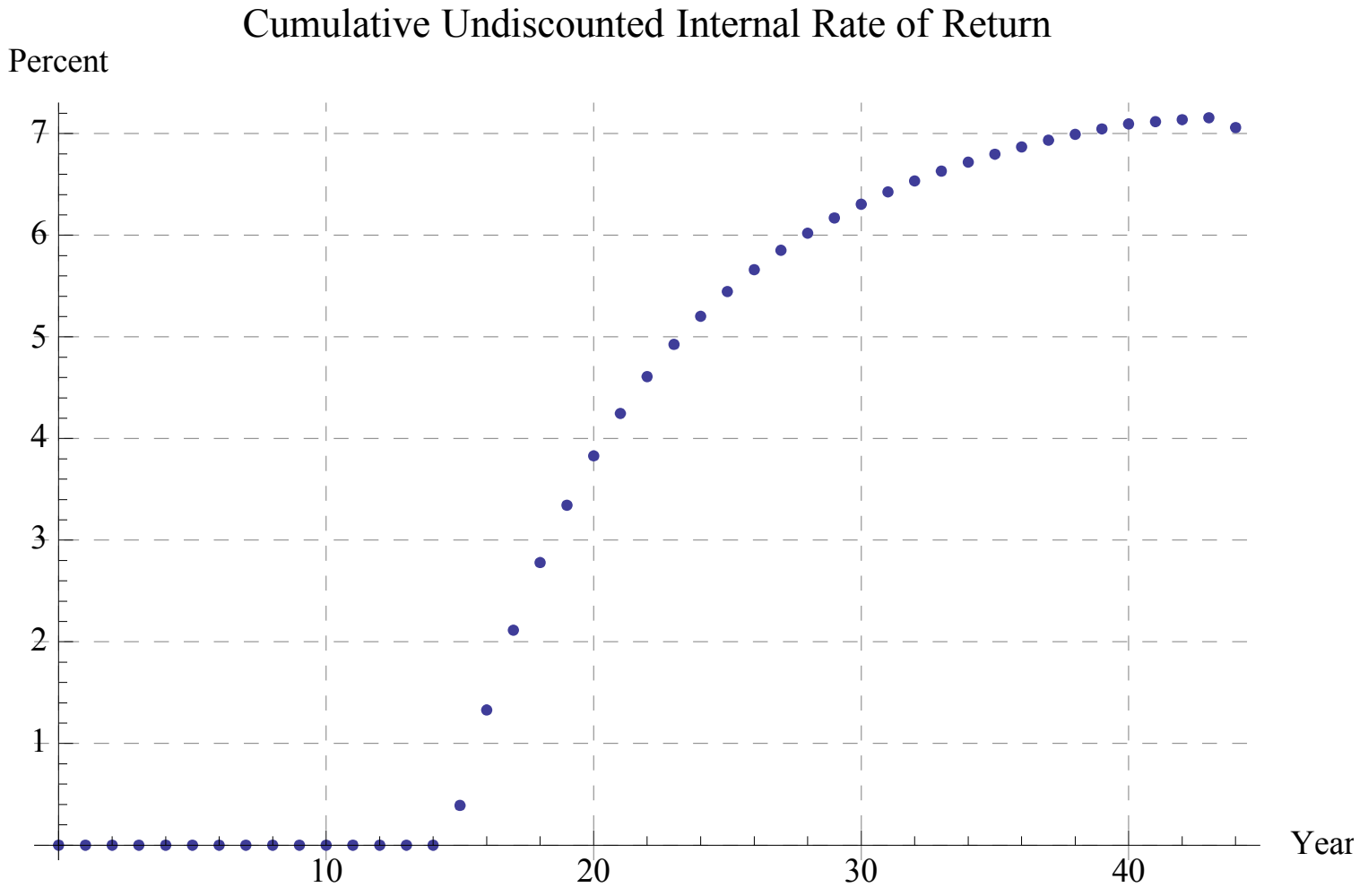

Fig. 27. Future market rate effects on multi-unit SMR internal rate of return.

The undiscounted rate of return is only around $7 \%$ after 40 years.

However, this assumes that the change from 2010 and 2020 will be similar to the change from 2000 to 2010. If the change from 1990 to 2000 is more appropriate, that is, essentially no change at all, then the economic case for SMRs - or for nuclear in general - is not favorable. The Energy Information Administration (EIA) Reference Case from the Annual Energy Outlook 2011 actually shows a slight decrease in the market rate [8].

Obviously, the market plays a large part in the economic feasibility and attractiveness of SMR deployment. Some regions have higher wholesale rates than others, so regional market analysis must play a prominent role in the economic analysis of SMRs. Similarly, the market analysis must somehow reflect the rather large amount of time that will elapse from the decision to build a plant to its startup. The market rate for electricity today is not necessarily the market rate for electricity tomorrow.

\subsection{MARKET EFFECTS ON LARGE REACTORS}

This case applies the current and future market effects to the large reactor case (Section 3.1) to see the effects. The only difference between this case and the base case is the market price of electricity. Then the assumptions are as follows:

- $3000 \mathrm{MWt}$

- $33.3 \%$ thermal efficiency

- $90 \%$ capacity factor 
- 5 year construction period

- 40 year lifetime

- $\$ 5000 / \mathrm{kWe}$

- D\&D costs $25 \%$ of construction

- $3 \%$ discount rate

- $\quad \$ 50 / M W h$ and $\$ 75 / \mathbf{M W h}$ market rates

- $5 \%$ interest rate during construction and payback

- $5 \%$ interest earned on D\&D sinking fund

Figure 28 shows the discounted cumulative cash flow for the large reactor at $\$ 50 / \mathrm{MWh}$. It shows a performance decrement relative to the SMR case in Section 3.6, not breaking even through the first 40 years of operation.

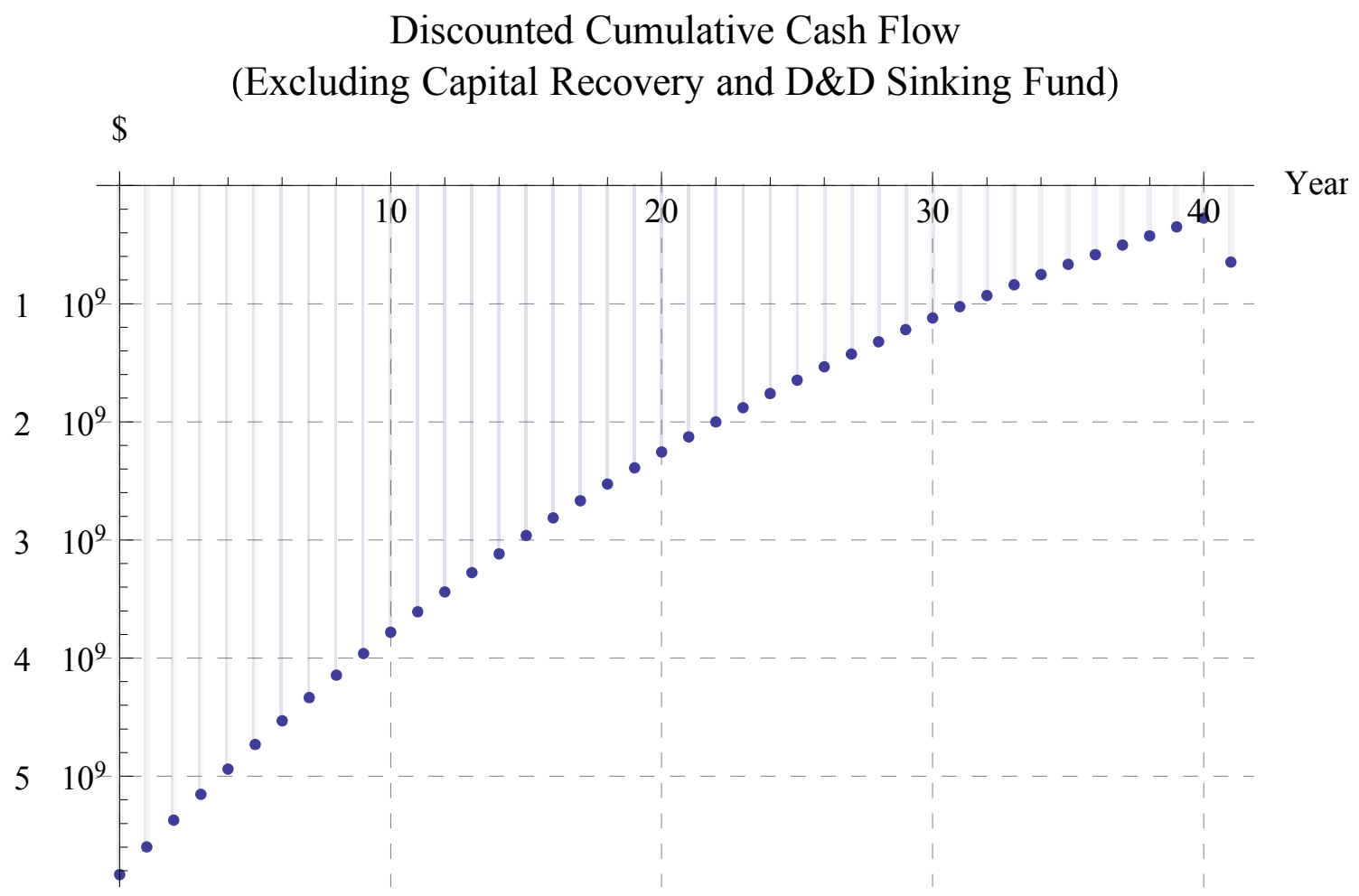

Fig. 28. Current market rate effects on single-unit large reactor discounted cash flow.

Figure 29 shows the discounted cumulative cash flow at \$75/MWh. The breakeven period for the large reactor is almost identical to the breakeven period for the multi-unit SMR. 


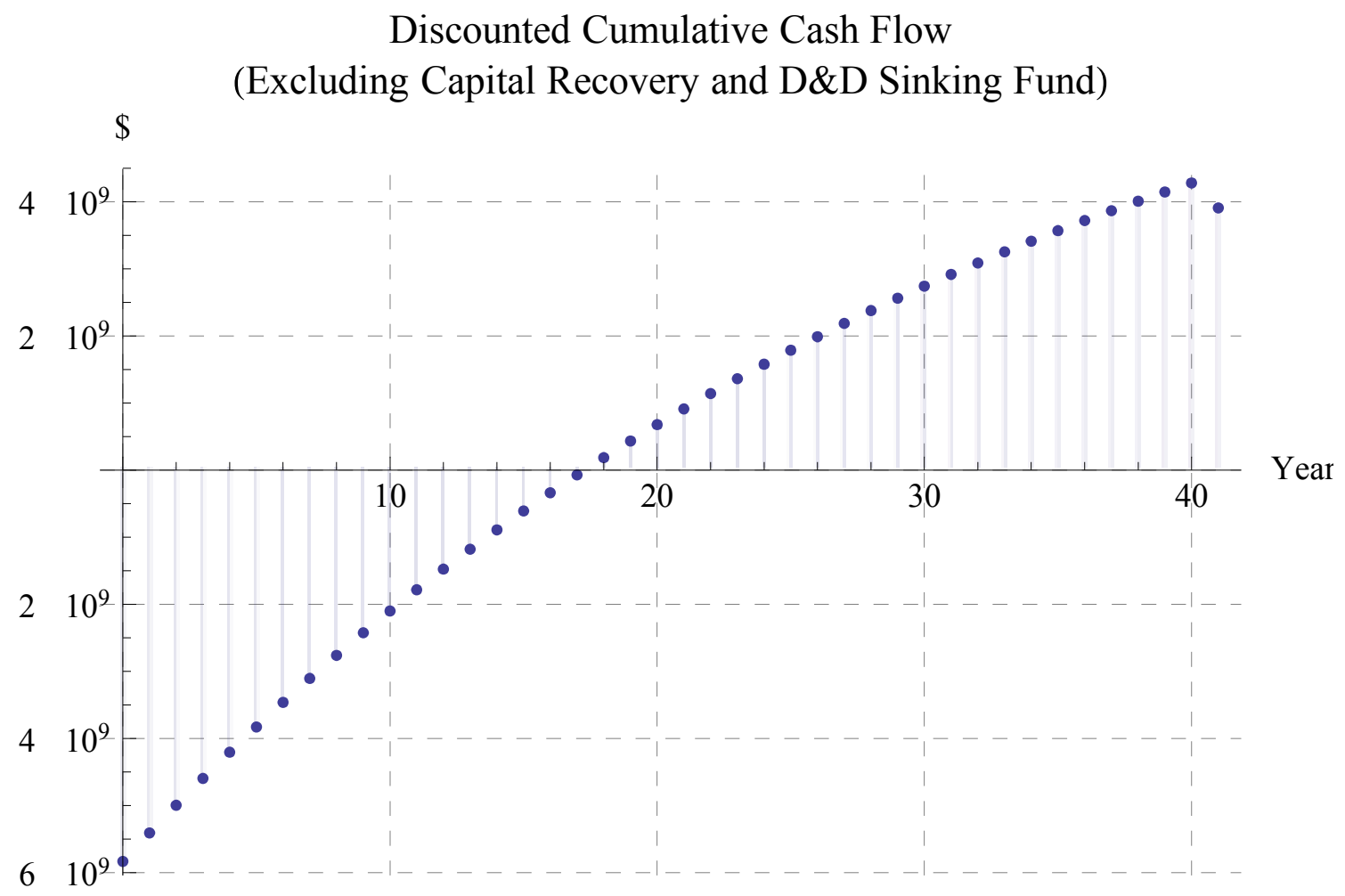

Fig. 29. Future market rate effects on single-unit large reactor discounted cash flow.

Figure 30 shows the IRR. The IRR reaches its maximum at approximately $7 \%$ at the end of the reactor life, somewhat lower than the multi-unit SMR case. 


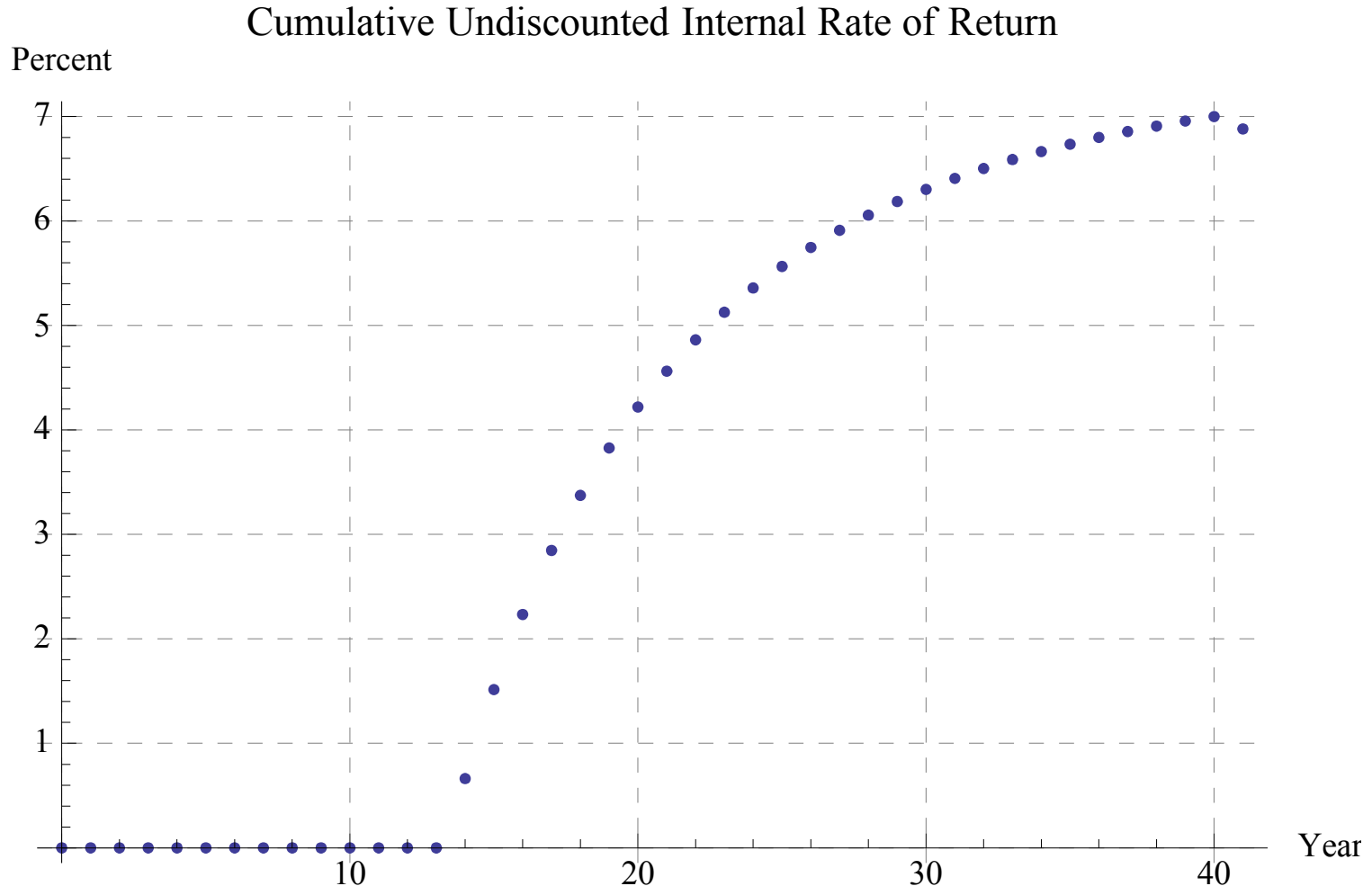

Fig. 30. Future market rate effects on single-unit large reactor IRR.

The driver for the difference between the large reactor case and the small reactor case is, again, the difference in the interest accrued during construction. If the SMR can achieve a shorter construction period and receive a lower interest rate during construction, the SMR can compete with the large reactor for baseload generation. 


\section{SUMMARY}

G4-ECONS has been modified, and requires further modification, to account for differences in its initial assumptions and the complexities of analyzing SMR deployment. These modifications include:

- market rates and their effects on economic attractiveness

- variations in capacity factor and their effects on the cash flow

- capital recovery options for accelerated payback

- multi-unit deployment options to account for SMR deployment strategies

The currently-planned modifications that have not been fully implemented include:

- FOAK to NOAK costs, incorporating a learning curve estimator

- uncertainty analysis to identify cost areas and factors that drive the overall uncertainty

The preliminary analysis using nominal values for construction and operation parameters demonstrates that SMRs face economic challenges in the typical electric market. The discounted breakeven period for SMRs - and for nuclear reactors in general - is such that any investor must have a realistic picture of the investing horizon.

The cost of electricity used in the first part of the analysis - $\$ 100 / \mathrm{MWh}-$ is the national retail average in 2012. Using that as the basis, there is a good economic case for SMR deployment when executed conscientiously. Moving the analysis from the retail domain to the wholesale domain completely changes the picture. The recently announced closure of Kewaunee demonstrates the difficulty in competing in the wholesale market without a power purchase agreement to guarantee revenue. Even accounting for a large, but not unprecedented, increase in the wholesale price only shifts the results a relatively small amount in nuclear's favor.

One immediate conclusion is that a potential market for SMRs is on the demand side, rather than the supply side. If a customer had sufficient demand, building a dedicated SMR would move that customer from paying retail rates to effectively paying wholesale rates. However, the benefit of building a dedicated SMR would have to be weighed against the large capital cost involved.

This is not the only potential market, but the questions asked above require further analysis. This report showed the changes made to G4-ECONS to start answering those questions. Based on the analysis performed, SMRs can achieve a kind of economy of their own scale by building multiple units at a single site. This as yet does not include learning curve effects on the costs of the nuclear reactors themselves, so there may be more potential for cost reduction.

Other potential market concepts have not been evaluated, such as repowering retired coal plant sites, collocation with industrial facilities, or dedicated military site installation. These all represent changes in the capital structure (repowered coal sites) or market structure (collocated/dedicated sites) that require changes in the model approach, as well as changes in the analytical approach.

There are other benefits that have not been quantified yet, including safety and grid compatibility effects. These will be the subject of future work. 


\section{FUTURE WORK}

The most immediate future work is to complete the compatibility of the new interface with the new computation engine in Mathematica. The next step is to fully implement uncertainty analysis and the learning curve information. These changes and additions to the model are part of the current economic analysis effort.

For proposed future work, grid effects and safety effects should be quantified. The model must also implement non-traditional power markets to account for SMR niche applications, such as in the 10s of MWe regime.

Follow-on work in SMR economics would include the generation of an optimizing engine for SMR deployment policies. Further potential future work would examine SMRs in a dynamic market environment, incorporating other power sources and other products, such as process heat and desalination. This work can be coupled with GIS-based information to extract more accurate labor and commodity costs, as well as grid-based deployment planning.

Nuclear construction and deployment is such a time- and capital-intensive endeavor that decisions made now must make every attempt to account for market conditions in the immediate, near-term, and long-term future. Follow-on work can be focused on finding methods to mitigate the inherent uncertainty that the long planning horizon represents. 


\section{REFERENCES}

1. International Atomic Energy Agency, "Power Reactor Information System," www.iaea.org/pris.

2. R. D. Stewart, R. M. Wyskida, and J. D. Johannes, Cost Estimator's Reference Manual, 2nd edition, Wiley, 1995.

3. D. E. Shropshire et al., Advanced Fuel Cycle Cost Basis, INL/EXT-07-12107, Rev. 2, Idaho National Laboratory, Idaho Falls, Idaho, 83415, December 2009.

http://www.osti.gov/bridge/searchresults.jsp?formname=searchform\&searchFor=advanced fuel cycle cost basis\&Author="K. A. Williams"

4. http://www.eia.gov/electricity/data.cfm, table_5_03.xlsx (average retail price of electricity $(\$ 100 / \mathrm{MWh})$

5. http://www.nei.org/resourcesandstats/nuclear_statistics/costs, average costs of nuclear power

6. http://www.eia.gov/todayinenergy/detail.cfm?id=9510, average wholesale price of electricity $(\$ 50 / \mathrm{MWh})$

7. http://www.eia.gov/electricity/data.cfm, avgprice_annual.xls (historic retail price of electricity)

8. http://www.eia.gov/forecasts/archive/aeo11/MT_electric.cfm

\section{GENERAL REFERENCES}

M. D. Carelli et al., "Economic features of integral, modular, small-to-medium size reactors," Progress in Nuclear Energy 52, 403-414 (2010).

Yangbo Du and John E. Parsons, Capacity Factor Risk at Nuclear Power Plants, Massachusetts Institute of Technology, January 2012.

Economic Modeling Working Group of the Generation IV International Forum, Cost Estimating Guidelines for Generation IV Nuclear Energy Systems, Rev. 4.2, Sept. 26, 2007, http://www.gen-4.org/Technology/horizontal/EMWG_Guidelines.pdf

A. Miroyannis, Estimation of ship construction costs, thesis, Massachusetts Institute of Technology, 2006.

K. A. Williams, The G4-ECONS Economic Evaluation Tool for Generation IV Reactor Systems, http://www.ornl.gov/ webworks/cppr/y2007/pres/125436.pdf 
